\title{
Investigation of discrepancies in satellite rainfall estimates over Ethiopia
}

Article

Published Version

Young, M. P., Williams, C. J. R., Chiu, J. C., Maidment, R. and Chen, S.-H. (2014) Investigation of discrepancies in satellite rainfall estimates over Ethiopia. Journal of Hydrometeorology, 15. pp. 2347-2369. ISSN 1525-7541 doi:

https://doi.org/10.1175/JHM-D-13-0111.1 Available at https://centaur.reading.ac.uk/38559/

It is advisable to refer to the publisher's version if you intend to cite from the work. See Guidance on citing.

Published version at: http://journals.ametsoc.org/doi/abs/10.1175/JHM-D-13-0111.1

To link to this article DOI: http://dx.doi.org/10.1175/JHM-D-13-0111.1

Publisher: American Meteorological Society

All outputs in CentAUR are protected by Intellectual Property Rights law, including copyright law. Copyright and IPR is retained by the creators or other copyright holders. Terms and conditions for use of this material are defined in the End User Agreement.

\section{www.reading.ac.uk/centaur}

\section{CentAUR}

Central Archive at the University of Reading 
Reading's research outputs online 


\title{
Investigation of Discrepancies in Satellite Rainfall Estimates over Ethiopia
}

\author{
Matthew P. Young, Charles J. R. Williams, J. Christine Chiu, and Ross I. Maidment \\ Department of Meteorology, University of Reading, Reading, United Kingdom \\ SHU-HuA CHEN \\ Department of Land, Air and Water Resources, University of California, Davis, Davis, California
}

(Manuscript received 10 July 2013, in final form 24 April 2014)

\begin{abstract}
Tropical Applications of Meteorology Using Satellite and Ground-Based Observations (TAMSAT) rainfall estimates are used extensively across Africa for operational rainfall monitoring and food security applications; thus, regional evaluations of TAMSAT are essential to ensure its reliability. This study assesses the performance of TAMSAT rainfall estimates, along with the African Rainfall Climatology (ARC), version 2; the Tropical Rainfall Measuring Mission (TRMM) 3B42 product; and the Climate Prediction Center morphing technique (CMORPH), against a dense rain gauge network over a mountainous region of Ethiopia. Overall, TAMSAT exhibits good skill in detecting rainy events but underestimates rainfall amount, while ARC underestimates both rainfall amount and rainy event frequency. Meanwhile, TRMM consistently performs best in detecting rainy events and capturing the mean rainfall and seasonal variability, while CMORPH tends to overdetect rainy events. Moreover, the mean difference in daily rainfall between the products and rain gauges shows increasing underestimation with increasing elevation. However, the distribution in satellite-gauge differences demonstrates that although $75 \%$ of retrievals underestimate rainfall, up to $25 \%$ overestimate rainfall over all elevations. Case studies using high-resolution simulations suggest underestimation in the satellite algorithms is likely due to shallow convection with warm cloud-top temperatures in addition to beam-filling effects in microwavebased retrievals from localized convective cells. The overestimation by IR-based algorithms is attributed to nonraining cirrus with cold cloud-top temperatures. These results stress the importance of understanding regional precipitation systems causing uncertainties in satellite rainfall estimates with a view toward using this knowledge to improve rainfall algorithms.
\end{abstract}

\section{Introduction}

Africa is vulnerable to prolonged periods of drought and floods that lead to food insecurity (Devereux 2007; Boyd et al. 2013). To monitor and help improve food security, accurate and detailed rainfall observations are required. However, Africa has one of the sparsest rain gauge networks in the world (Washington et al. 2006), and rain gauge observations have declined significantly in the past 20 years (Lorenz and Kunstmann 2012). Fortunately, satellites provide an alternative way to estimate precipitation at high spatial and temporal resolutions and are therefore ideal for monitoring and

Corresponding author address: Matthew Young, Department of Meteorology, University of Reading, P.O. Box 243, Reading, RG6 6BB, United Kingdom.

E-mail: m.young@pgr.reading.ac.uk providing early warnings of drought and flooding (Verdin et al. 2005).

Satellite measurements from geostationary infrared (IR) and low-Earth-orbiting passive microwave (MW) instruments are widely used to estimate surface rainfall. IR-based methods use empirical relationships to retrieve rainfall from cloud-top brightness temperature, assuming that precipitation originates from convective clouds that penetrate deep into the atmosphere and thus have cold cloud tops (e.g., Arkin and Meisner 1987; Grimes et al. 1999; Novella and Thiaw 2013). Such an assumption works well for precipitation associated with cold cloud, but it unavoidably fails to detect precipitation associated with warm clouds (Petty 1999; Chen et al. 2011) and mistakes nonprecipitating cirrus as raining (Adler and Negri 1988; Todd et al. 1995, 1999). In contrast, MW measurements directly sense the emission and scattering of radiation due to hydrometeors and provide physically 
based and potentially more accurate rainfall estimates. However, satellite MW observations are less frequent than IR measurements, with typically two overpasses per day over a location, except for those of the Tropical Rainfall Measuring Mission (TRMM) Microwave Imager (TMI), which operates in a low-inclination orbit. To improve both accuracy and sampling frequency of surface rainfall estimates, many retrieval methods have used both IR and MW observations, such as the Climate Prediction Center (CPC) morphing technique (CMORPH; Joyce et al. 2004) and the TRMM Multisatellite Precipitation Analysis (TMPA; hereafter referred to as TRMM 3B42; Huffman et al. 2007). These algorithms use varying procedures to combine information obtained from the IR and MW measurements as described in section 2a.

Of the few satellite rainfall products designed specifically for Africa, the Tropical Applications of Meteorology Using Satellite and Ground-Based Observations (TAMSAT; Grimes et al. 1999; Tarnavsky et al. 2014) algorithm is used over the African continent (e.g., West Africa and the Sahel and Ethiopia and Uganda in East Africa) for operational climate monitoring and agricultural and food security applications. Based on IR observations, TAMSAT relates the time duration of IR cloud-top temperature below a rain/no-rain threshold temperature to surface rainfall. TAMSAT estimates are currently produced every 10 days (dekad) in real time.

Previous regional evaluations from Dinku et al. (2007) demonstrated that 10-day rainfall estimates from TAMSAT performed as well as those from CMORPH and TRMM (version 6) over Ethiopia's central highlands, although in their study the effects of elevation were not investigated. However, TAMSAT underestimated surface rainfall over a region of southern Africa with complex topography (Thorne et al. 2001). Mountainous areas present a barrier for airflow resulting in strong orographic uplift that significantly influences precipitation formation and complicates the rainfall characteristics (Houze 2012). This, in turn, may introduce additional retrieval difficulties for satellitebased methods. As shown in Fig. 1, Ethiopia has varying terrain from low-lying plains and valleys in the southeast to high mountains reaching above $4000 \mathrm{~m}$ in the central and northern regions, providing challenging topography for satellite-based rainfall estimates. As a result, a number of studies have focused on rainfall evaluations in Ethiopia against limited rain gauge data (Hirpa et al. 2010; Romilly and Gebremichael 2011; Habib et al. 2012).

Elevation-dependent biases have been found in satellite surface rainfall estimates over the Ethiopian highlands. In general, overestimations in annual-mean rainfall during 2003-07 are found at lower elevations

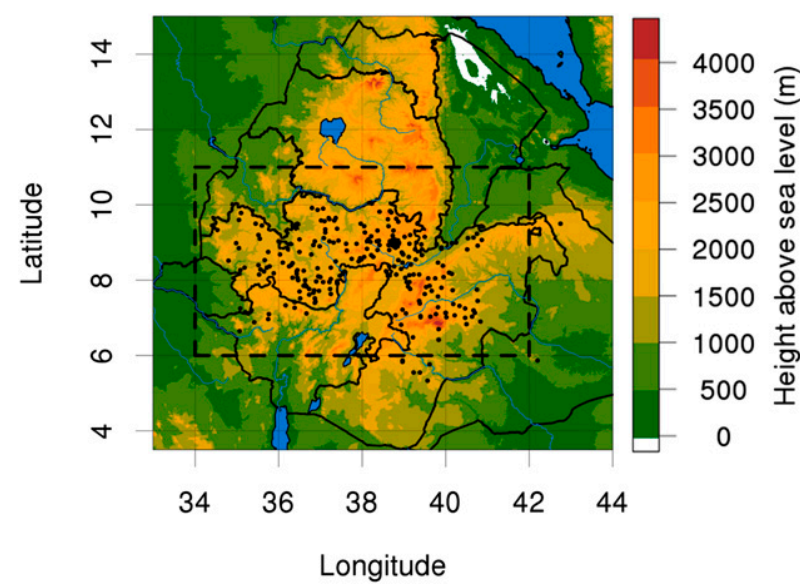

FIG. 1. Elevation (m) of Ethiopia and rain gauge positions (black dots). The dashed box represents the Oromia region.

between 500 and $2000 \mathrm{~m}$ in CMORPH and TRMM (Romilly and Gebremichael 2011), but Habib et al. (2012) only confirmed overestimation in CMORPH and did not find this feature present in TRMM over the years 2003-10. In contrast, underestimations have been found at higher elevations above $2000 \mathrm{~m}$ in both CMORPH and TRMM (Romilly and Gebremichael 2011; Habib et al. 2012).

These elevation-dependent discrepancies between satellite estimates and rain gauge measurements over the Ethiopian highlands stress the need for more observational evidence and advanced understanding of sources of retrieval errors. The objective of this paper is to investigate whether such discrepancies are present in TAMSAT rainfall observations and, in particular, whether they have strong dependence on elevation. We will compare TAMSAT retrievals to other benchmark rainfall products, such as the African Rainfall Climatology (ARC; Novella and Thiaw 2013), TRMM, and CMORPH. These intercomparisons will be conducted on a basis of daily rather than dekad rainfall estimates, to better characterize the potential sources of error at shorter time scales due to localized conditions that may have a significant effect on the skill of dekad rainfall estimates of TAMSAT. We also take advantage of daily rain gauge observations and high-resolution simulations from the Weather Research and Forecasting (WRF) Model to help identify potential sources of errors. We are aware that simulations over complex topography can be highly uncertain. However, we only use simulations to understand the cloud microphysical content and to qualitatively explain potential sources of retrieval errors.

In this paper, section 2 briefly describes datasets and methods, including TAMSAT, a number of benchmark 
TABLE 1. Summary of the satellite rainfall products used in this study and their spatial and temporal characteristics.

\begin{tabular}{llccc}
\hline \hline \multicolumn{1}{c}{ Product } & Retrieval method & Time period available & Spatial resolution $\left(^{\circ}\right)$ & Temporal resolution \\
\hline TAMSAT & IR + gauge & 1983-present & 0.0375 & Daily \\
ARC & IR + gauge & 1983-present & 0.1 & Daily \\
TRMM 3B42 & MW + IR + gauge & 1998-present & 0.25 & 3 hourly \\
CMORPH & MW & 1998-present & 0.25 & 3 hourly \\
\hline
\end{tabular}

satellite rainfall products, rain gauge measurements, model simulations, and evaluation metrics. Section 3 presents evaluation results and error dependency on elevation with a focus over the Ethiopian highlands. Finally, section 4 summarizes the main findings of this work.

\section{Data and methodology}

\section{a. Satellite rainfall estimates}

This section describes four satellite rainfall products (TAMSAT, ARC, TRMM, and CMORPH) used in this work, with spatial resolutions from $0.0375^{\circ}$ to $0.25^{\circ}$ and temporal resolutions from 3 hourly to daily (Table 1 ). For our analysis, all satellite estimates were spatially averaged to a $0.25^{\circ}$ grid resolution; the 3-hourly TRMM and CMORPH estimates were accumulated to daily rainfall starting from 0600 UTC each day to coincide with the measurement time periods of TAMSAT and ARC.

\section{1) TAMSAT}

TAMSAT rainfall estimates (Grimes et al. 1999; Maidment et al. 2012, 2014; Tarnavsky et al. 2014) are based on linear relationships between surface rainfall and the number of hours when the brightness temperatures of IR pixels fall below a certain rain/no-rain threshold temperature, that is, cold cloud duration (CCD). Optimal threshold temperatures and calibration parameters are derived by comparing $\mathrm{CCD}$ at various temperature thresholds to a large database of historic rain gauge observations (Tarnavsky et al. 2014). The calibration varies both by region and month to account for local and seasonal variations in the relationship between cloud-top temperature and rainfall but remains climatologically homogenous in that it does not vary from one year to the next. This homogeneity is a unique feature of TAMSAT in comparison with other satellite products that undergo continuous adjustments to rain gauge data (e.g., TRMM; Maidment et al. 2014).

In this study we use a newly developed TAMSAT daily estimate derived by disaggregating the 10-day rainfall totals. Details of the disaggregation method can be found in Maidment et al. (2012).

\section{2) ARC (VERSION 2)}

Version 2 of ARC (Novella and Thiaw 2013) uses geostationary IR and rain gauge data from the Global Telecommunications System (GTS) to provide daily (0600-0600 UTC) rainfall estimates over Africa for famine early warning. The retrieval algorithm comprises three main steps. First, an initial rain-rate estimate of $3 \mathrm{~mm} \mathrm{~h}^{-1}$ is assigned to any IR pixel with cloud-top temperatures lower than $235 \mathrm{~K}$. Second, using a maximum likelihood technique, this initial estimate is then weighted toward the nearest available GTS gauge observations. Finally, the weighted satellite-based estimate is merged with the GTS gauge observations by solving a Poisson's equation such that the satellite component primarily describes the spatial precipitation field, while the GTS gauge observations determine the magnitude.

\section{3) TRMM 3B42 (VERSION 7)}

TRMM 3B42 (Huffman et al. 2007) combines observations from passive MW, geostationary IR, and rain gauges. Several low-Earth-orbiting MW sensors are used, namely the TMI, the Special Sensor Microwave Imager (SSM/I), the Advanced Microwave Sounding Unit-B (AMSU-B), and the Advanced Microwave Scanning Radiometer for Earth Observing System (AMSR-E). The Goddard profiling algorithm (GPROF; Kummerow et al. 2001) is used to derive MW-based rain rates (except AMSU-B). Using a Bayesian framework, GPROF matches sensor-observed brightness temperatures to those produced from simulated vertical hydrometeor profiles in a database to select the best profile and corresponding rain rate. The final MW sensor, AMSU-B with five channels between 89 and $183.3 \mathrm{GHz}$, is sensitive to ice-phase hydrometeors. Rainfall estimates from AMSU-B are therefore obtained by relating

TABLE 2. Contingency table used to evaluate rainfall occurrence. Parameters $A-D$ represent the number of hits, false alarms, misses, and correct negatives, respectively.

\begin{tabular}{ccc}
\hline \hline & \multicolumn{2}{c}{ Gauge } \\
\cline { 2 - 3 } Satellite & Yes & No \\
\hline Yes & $A$ & $B$ \\
No & $C$ & $D$ \\
\hline
\end{tabular}


TABLE 3. Definitions and descriptions of metrics for rainfall occurrence evaluation. Parameters $A-D$ represent the number of hits, false alarms, misses, and correct negatives defined in contingency table (see Table 2).

\begin{tabular}{cll}
\hline \hline Evaluation metric & \multicolumn{1}{c}{ Definition } & \multicolumn{1}{c}{ Remark } \\
\hline FB & $=\frac{A+B}{A+D}$ & \\
& $=\frac{A}{A+C}$ & $\mathrm{FB}=1$, perfect \\
POD & $=\frac{B}{A+B}$ & $\mathrm{FB}>1$, overestimated \\
FAR & $2(A D-B C)$ & $0 \leq \mathrm{POD}<1$, underdetected \\
HSS & $=\frac{\mathrm{POD}=1 \text {, perfect }}{(A+C)(C+D)+(A+B)(B+D)}$ & $0<\mathrm{FAR} \leq 1$, overdetected \\
& & FAR $=0$, perfect \\
& & HSS $<0$, indicates chance better \\
& & HSS $=0$, no skill \\
& & $0<\mathrm{HSS}<1$, some skill relative to chance \\
\end{tabular}

retrieved ice water path (IWP) to rain rate, using relationships built from cloud-resolving model (CRM) simulations (Zhao and Weng 2002; Weng et al. 2003). All of these MW-based rainfall estimates are intercalibrated against TMI and TRMM precipitation radar retrievals and then combined onto the same grid.

Rain-rate estimates from geostationary IR radiances are derived by matching the histograms of coincident observations of MW-based rainfall estimates and IR brightness temperatures. While the MW estimates are applied where available, the IR-based estimates are used to fill any gaps between the MW overpasses. Finally, rainfall estimates are scaled to the monthly rainfall product provided by the Global Precipitation Climatological Centre (GPCC; Schneider et al. 2014).

\section{4) $\mathrm{CMORPH}$}

The National Oceanic Atmospheric Administration's (NOAA) CMORPH (Joyce et al. 2004) is based entirely on MW precipitation retrievals. The MW sensors used are TMI, AMSU-B, and SSM/I. Similar to TRMM 3B42, GPROF is applied to TMI observations while the IWPprecipitation relationship derived from CRMs is used for AMSU-B. The SSM/I retrievals are derived from the NOAA SSM/I rainfall algorithm that relates surface rain rate to the $85-\mathrm{GHz}$ scattering signal due to suspended ice hydrometeors (Ferraro 1997). After combining all the available MW estimates, CMORPH applies snow and ice surface screening to remove artificial estimates over those surface types mistaken as ice-based hydrometeors. The algorithm then computes motion vectors from 30-min geostationary IR observations to track the movements of precipitating systems between MW overpasses. These vectors are applied to the MW retrievals to propagate them forward in space and time resulting in full gridded 3hourly precipitation fields. Note that unlike the three other satellite products, CMORPH only comprises
MW-based rainfall estimates and is not scaled or calibrated to rain gauge observations.

\section{b. Rain gauge data}

We evaluate satellite rainfall estimates using rain gauge data across the Oromia region of Ethiopia (Fig. 1), provided by the National Meteorology Agency of Ethiopia. This originally consisted of daily rainfall measurements from 276 stations during 2002-06. The number of stations was reduced to 222 after rigorous quality control by intercomparing neighboring stations and removing duplicated entries and suspiciously high values. To evaluate

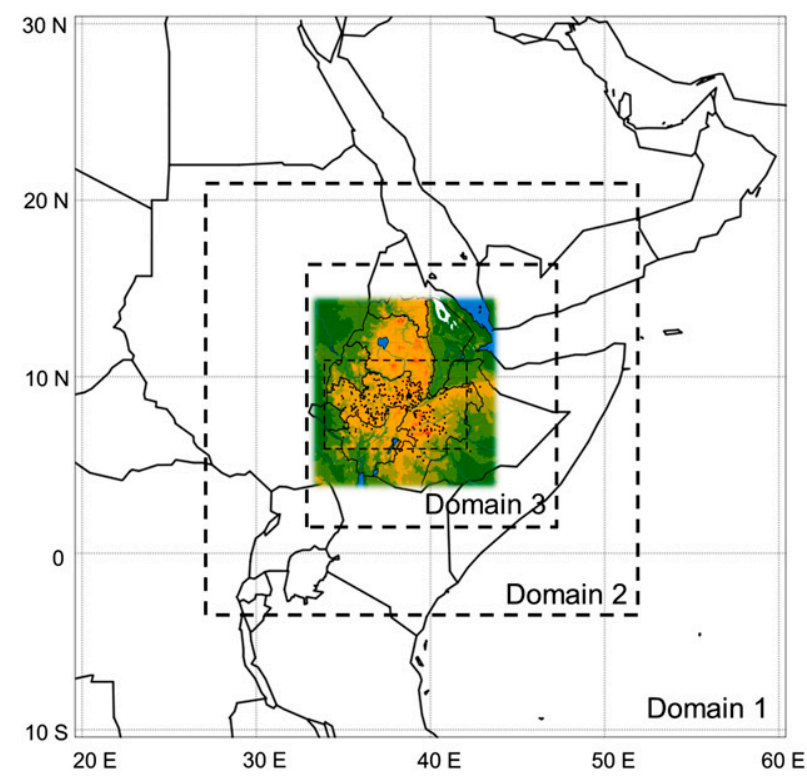

FIG. 2. The three nested domains used in WRF simulations with resolutions of 27,9 , and $3 \mathrm{~km}$. The numbers of grid points in the $x-y-z$ directions for domains $1-3$ are $160 \times 160 \times 31,301 \times 301 \times$ 31 , and $541 \times 541 \times 31$, respectively. Domain 3 , which covers Ethiopia, is the main area of interest in this study. Figure 1 is coplotted in Domain 3 for illustration. 


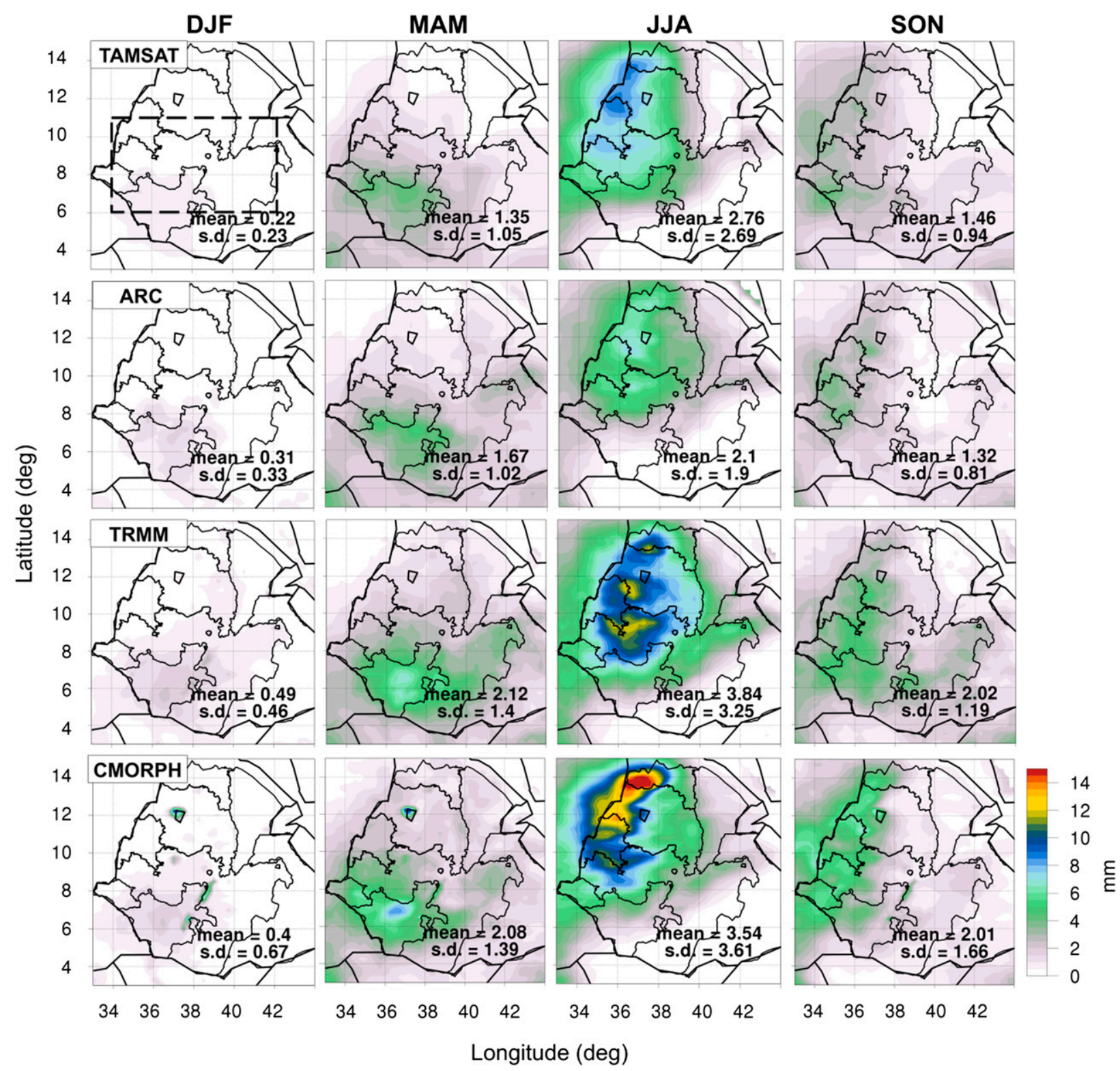

FIG. 3. Spatial distributions of daily mean rainfall (mm) over Ethiopia during 2002-06 for (from left to right) DJF, MAM, JJA, and SON from satellite rainfall products (from top to bottom) TAMSAT, ARC, TRMM 3B42, and CMORPH. The dashed box (DJF, TAMSAT) bounds the Oromia region.

the performance of satellite-based rainfall retrievals at pixel scale, rain gauge data were further spatially interpolated and gridded to $0.25^{\circ}$ resolution using kriging (Barancourt et al. 1992) that has been applied to many satellite-gauge validation studies (e.g., Dinku et al. 2011; Chadwick and Grimes 2012; Maidment et al. 2013). In addition, only the $0.25^{\circ}$ pixels containing at least one gauge were kriged and compared to the collocated satellite pixels. Note that, unfortunately, this rain gauge dataset was used to derive calibration coefficients for the TAMSAT 10-day rainfall product over Ethiopia and thus is not independent of TAMSAT retrievals. This is a known caveat throughout this work. However, as shown in section 3, the comparison allows us to evaluate the performance of TAMSAT against other benchmark satellite products and investigate the skill of the current calibration at capturing temporal and spatial rainfall distributions over complex topography in Ethiopia.

\section{c. Evaluation methods}

To evaluate the ability of the satellite estimates at detecting rainfall events and also the magnitude of 

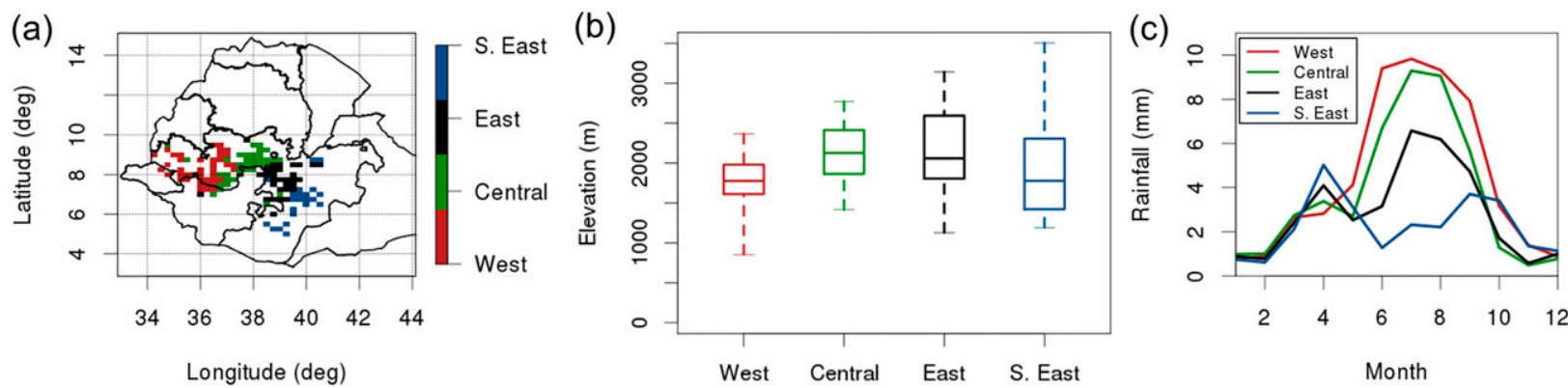

FIG. 4. (a) The spatial extent, (b) the elevation range, and (c) the annual cycle of daily mean rainfall in the four climatic regions over Oromia. These regions are defined by their distinct annual cycles observed in kriged rain gauge data at a resolution of $0.25^{\circ}$ during $2002-06$.

rainfall, we assess both rainfall occurrence and rainfall amount between the collocated $0.25^{\circ}$ satellite and gauge pixels during 2002-06. For rainfall occurrence, observations are evaluated using contingency tables (Table 2) from which the following skill metrics are derived (Table 3): frequency bias (FB), probability of detection (POD), false alarm ratio (FAR), and Heidke skill score (HSS). The FB determines whether the satellite over- or underdetects the number of rain events; any value greater (less) than the perfect score of 1 suggests overdetection (underdetection) of rain events. The POD and FAR can be used in conjunction such that high POD and low FAR indicate best detection. In comparison to these metrics, the HSS is advantageous because it measures the ability of the satellite to observe rain events relative to events that occur at random. Thus, the HSS indicates skill when rain events detected because of random chance have been removed.

Additionally, conventional evaluation metrics are used to assess the estimates of rainfall amount (i.e., observations with nonzero rainfall): the bias measuring the mean difference between all satellite and gauge observations, where perfect estimates will have a bias of zero while those too high or too low will be above or below zero, respectively; and bias ratio, defined as the sum of the satellite estimates divided by the sum of rain gauge observations, with a score of 1 indicating perfect agreement. We also use the root-mean-square error (RMSE) and linear correlation coefficient. Note that the correlation coefficient measures the strength of the linear relationship between the satellite and gauge observations, which is not affected by linear systematic errors in either satellite or gauge data, but will be affected by a systematic nonlinear bias. Therefore, considering all metrics together is crucial for evaluation purposes.

\section{d. WRF Model simulations}

To help identify potential sources of discrepancy between satellite retrievals and rain gauge data, version 3.4 of WRF (Skamarock et al. 2008), a regional nonhydrostatic atmospheric model, is used to simulate the horizontal and vertical distribution of hydrometeors associated with precipitation systems. We configure nested domains 1-3 with resolutions of 27, 9, and $3 \mathrm{~km}$, as shown in Fig. 2, and allow two-way interactions between domains. The vertical resolution ranges from $\sim 100 \mathrm{~m}$ near the surface to $\sim 1 \mathrm{~km}$ at the upper levels. The numbers of grid points in the $x-y-z$ directions for domains $1-3$ are $160 \times 160 \times 31$, $301 \times 301 \times 31$, and $541 \times 541 \times 31$, respectively, with an emphasis on domain 3 that covers Ethiopia.

The initial and boundary conditions are from the National Centers for Environmental Prediction (NCEP) Global Forecast System Final (FNL) gridded analysis, which has a temporal resolution of $6 \mathrm{~h}$ and a spatial resolution of $1^{\circ} \times 1^{\circ}$. The time step for domain 1 is $120 \mathrm{~s}$. During the model runs, domain 1 above the boundary layer was nudged to the FNL analysis using fourdimensional data assimilation to prevent drifting of large-scale patterns. For numeric schemes, we chose the fifth-order advection scheme for the horizontal direction, because simulations using odd-ordered schemes are less noisy with similar accuracy to those from the next-higher even-ordered schemes; therefore, the fifthorder scheme is superior to even-ordered schemes (Wicker and Skamarock 2002). In addition, since errors in our simulations are dominated by the horizontal advection terms, because of a coarser resolution in the horizontal compared to the vertical (i.e., $3 \mathrm{~km}$ versus hundreds of meters), a lower third-order scheme is sufficient and is chosen for the vertical direction. For physics schemes, we use the Morrison two-moment microphysics parameterization (Morrison et al. 2005), the Yonsei University boundary layer parameterization (Hong et al. 2006), and the Goddard Space Flight Center short- and longwave radiation scheme (Chou and Suarez 1999; Chou et al. 2001) for all three domains. The GrellDévényi ensemble cumulus parameterization (Grell and Dévényi 2002) is used only for domains 1 and 2, because the resolution for domain 3 is sufficient to resolve convective systems. 

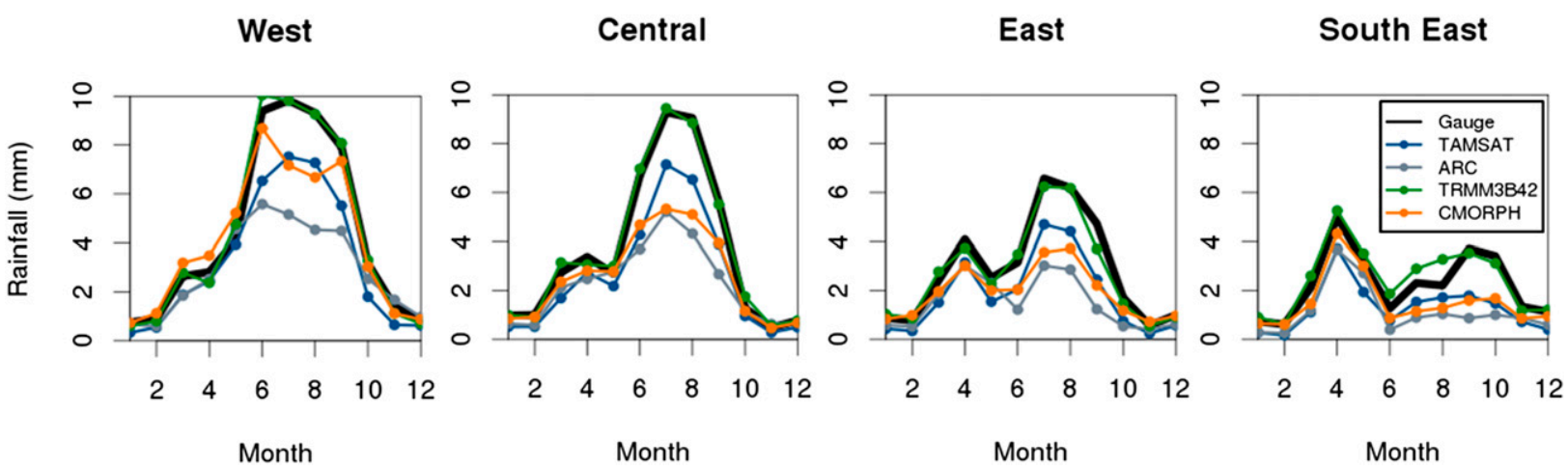

FIG. 5. Mean annual cycles of monthly daily mean rainfall from the gauge and satellite products during $2002-06$ for each of the rainfall zones presented in Fig. 4.

\section{Results}

\section{a. Satellite rainfall estimates during 2002-06}

In Ethiopia, the main rainy season (the long rains or Kiremt) is in June-August (JJA). In addition to this period, the south of the country experiences two other wet seasons (the short rains or Belg) in March-May (MAM) and September-November (SON), corresponding to the north- and southward propagations of the intertropical convergence zone (ITCZ), respectively. December-February (DJF) typically remains dry until the ITCZ moves northward again. These transitions between dry and wet seasons are well captured by satellite observations (as shown in Fig. 3). Overall, the wet summer season exhibits the widest daily rainfall range with maxima greater than $10 \mathrm{~mm}$. Not surprisingly, the dry winter season has the lowest mean and smallest variation of daily mean rainfall with maxima of up to $2 \mathrm{~mm}$.

The maximum daily rainfall over northwestern Ethiopia in JJA varies significantly between satellite observations; IR-based estimates from TAMSAT and ARC do not exceed $10 \mathrm{~mm}$, whereas MW-based rainfall estimates from TRMM and CMORPH are greater than $10 \mathrm{~mm}$. The high rainfall in TRMM and CMORPH may be due to large amounts of ice aloft that enhance the scattering signal in MW observations (Kummerow et al. 2001; Tompkins and Adebiyi 2012). Interestingly, magnitudes of TRMM rainfall estimates are somewhat between TAMSAT and CMORPH, suggesting calibrations against monthly gauge totals in TRMM estimates successfully reduce high rainfall estimates that are likely erroneous.

\section{b. Comparison to rain gauge measurements over Oromia}

We further focus on a detailed evaluation of rainfall estimates from TAMSAT and other satellite products over the Oromia region, capitalizing on the dense rain gauge observations as shown in Fig. 1. The relative location of Oromia to Ethiopia can also be found in Fig. 3. For such a large region $\left(\sim 285000 \mathrm{~km}^{2}\right)$, it is likely different parts of Oromia have their own distinct meteorological environment that controls rainfall variability, making it challenging to attribute retrieval errors to terrain elevation. To separate the influence of the large-scale meteorological environment from elevation more properly, we conducted a cluster analysis on the annual rainfall cycles, using the kriged rain gauge data at $0.25^{\circ}$ resolution; the cluster analysis consequently identified four distinct rainfall regions (Fig. 4), similar to those reported in previous studies for Ethiopia (e.g., Gissila et al. 2004; Dinku et al. 2007; Diro et al. 2008). Not surprisingly, these rainfall regions are highly dependent on their location and are therefore denoted as west, central, east, and southeast (Fig. 4a). Among these subregions, the central and eastern regions have

TABLE 4. Statistics of daily mean rainfall for collocated satellite and rain gauge observations over the four climatic rainfall regions in Oromia at $0.25^{\circ}$ pixel scale during 2002-06. Best performances for each evaluation metric are highlighted bold.

\begin{tabular}{|c|c|c|c|c|c|c|c|c|c|c|c|c|}
\hline & \multicolumn{4}{|c|}{ RMSE (mm) } & \multicolumn{4}{|c|}{ Bias ratio } & \multicolumn{4}{|c|}{ Correlation } \\
\hline & West & Central & East & Southeast & West & Central & East & Southeast & West & Central & East & Southeast \\
\hline TAMSAT & 7.16 & 6.90 & 6.62 & 6.65 & 0.83 & 0.81 & 0.74 & 0.75 & 0.32 & 0.31 & 0.29 & 0.25 \\
\hline $\mathrm{ARC}$ & 7.98 & 8.06 & 9.56 & 9.51 & 0.70 & 0.69 & 0.67 & 0.79 & 0.19 & 0.19 & 0.12 & 0.13 \\
\hline TRMM & 11.62 & 10.73 & 10.49 & 12.16 & 1.15 & 1.13 & 1.09 & 1.23 & 0.32 & 0.32 & 0.34 & 0.29 \\
\hline CMORPH & 9.37 & 8.48 & 8.57 & 10.30 & 0.97 & 0.75 & 0.66 & 0.82 & 0.24 & 0.24 & 0.26 & 0.35 \\
\hline
\end{tabular}




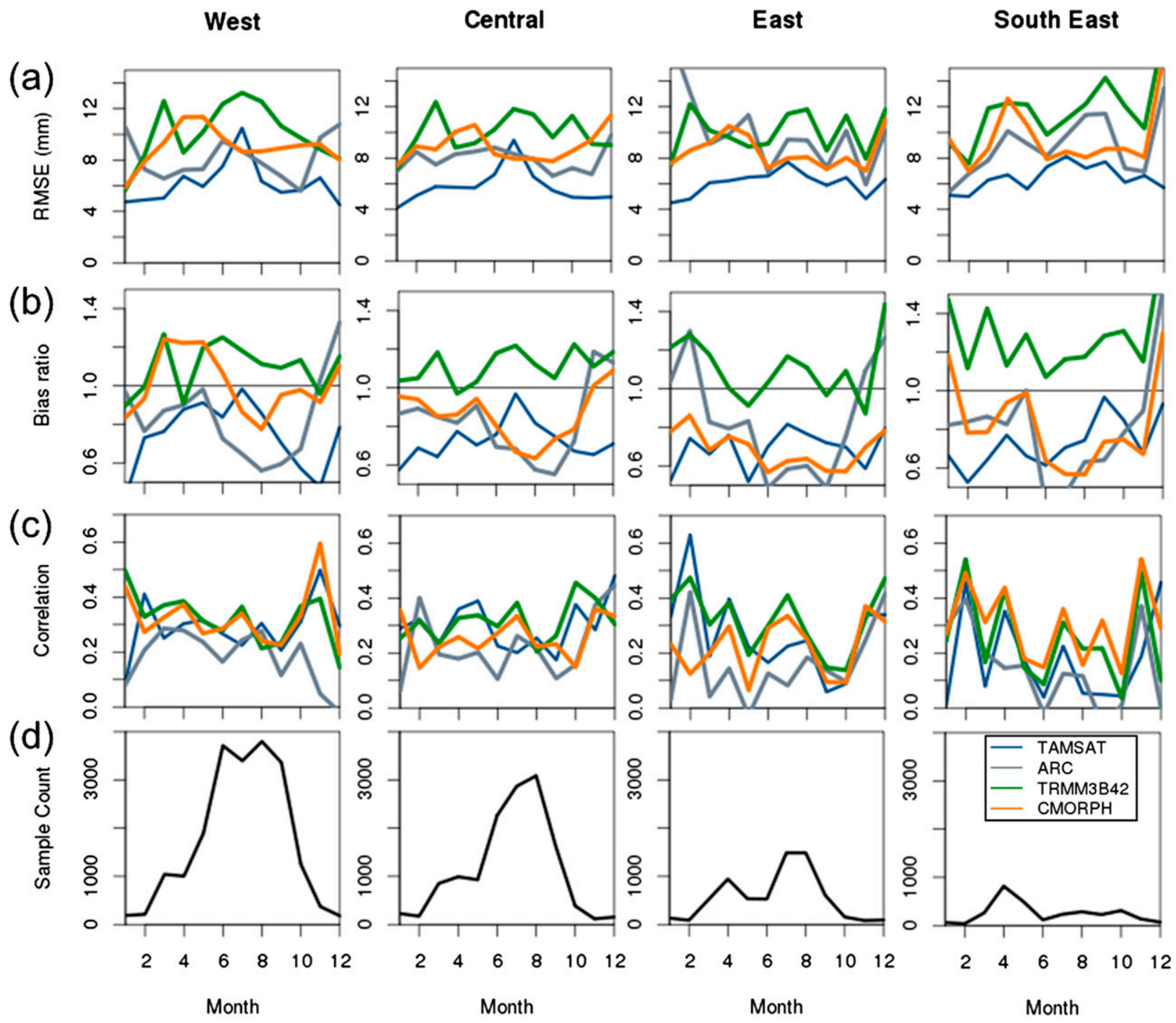

FIG. 6. Monthly (a) RMSE, (b) bias ratio, (c) linear correlation, and (d) number of coincident raining samples for collocated daily satellite and rain gauge observations at $0.25^{\circ}$ pixel scale during 2002-06. Statistics are presented for the four climatic rainfall regions with the total sample counts of around 20400 (west), 13670 (central), 6650 (east), and 3050 (southeast).

a mean elevation slightly larger than the west and southeast (Fig. 4b). However, in general, each individual subregion covers a similar range of elevations, which can be used to properly investigate to what extent the retrieval errors depend on elevation (see section $3 \mathrm{c}$ ).

As expected, these subregions have distinct rainfall cycles (Fig. 4c). The annual rainfall cycle changes from a unimodal pattern in the western and the central region to a bimodal pattern in the east and the southeast. The main peak of the unimodal annual cycle in the western region occurs from May to October with a maximum of $\sim 10 \mathrm{~mm}$. Over the central region, the peak of the annual cycle becomes narrower, meaning the rainfall increases in June (later than May in the western region) and decreases substantially in September (earlier than October in the western region). In contrast, the eastern and southeastern regions both experience bimodal annual cycles. The eastern region initially peaks at $4 \mathrm{~mm}$ in April, followed by a larger peak over July and August similar to the central region in timing but lower in magnitude. Relative to the other regions, the southeastern region uniquely experiences highest mean rainfall in April, with a prolonged and relatively light rainy season during June-November. For convenience, we define one wet period as June-September for the western and central regions, and two wet periods (March-May and July-October) for the eastern and southeastern regions. Any other months are referred to as dry periods. 
(a) West, August

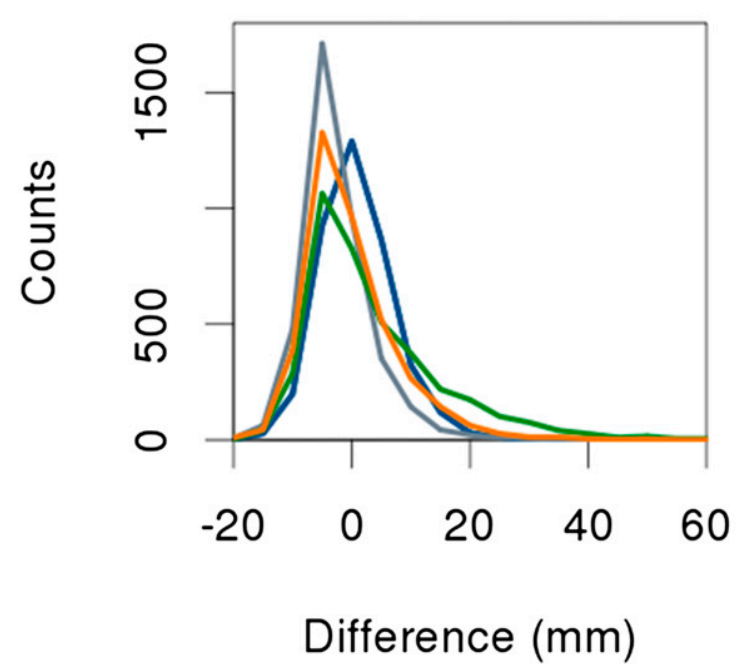

(b) South East, March

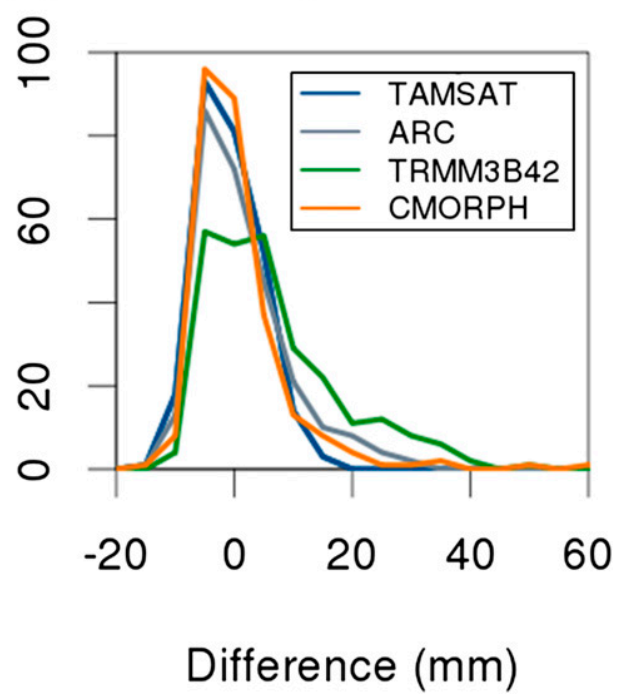

FIG. 7. Histograms of daily rainfall errors (retrievals minus rain gauge observations) in the (a) western region in August and (b) southeastern region in March.

These regionally distinct annual cycles observed from rain gauge data are further used to evaluate the satellite products, as shown in Fig. 5. Overall, TRMM 3B42 stands out and captures both the magnitudes and timing of the cycles well, reflecting that its rainfall estimates are well calibrated against monthly rain gauge data. On the other hand, TAMSAT, ARC, and CMORPH all underestimate the peak magnitudes of each cycle in all regions. Underestimation is most pronounced in ARC where its magnitude is almost half of the gauge data, particularly during June-August in the western, central, and eastern regions. It is worth noting that TAMSAT, ARC, and CMORPH all missed the secondary wet season during September-October in the southeastern region. This region is known to experience a monsoonal southerly flow that often induces the development of ice-free raining clouds, which are difficult to detect using current satellite algorithms (Romilly and Gebremichael 2011).

For evaluating satellite rainfall amount, Table 4 summarizes the performance of all products over these four climatic regions in Oromia during 2002-06, while Fig. 6 shows detailed monthly statistics of retrieval errors. Note that statistics are computed only when collocated daily satellite and rain gauge observations were coincidentally nonzero. Over all regions, TAMSAT has the lowest RMSE, which is not surprising because TAMSAT rainfall estimates were calibrated against these rain gauge observations (as explained in section 2b). In contrast, TRMM tends to have the largest RMSE, caused by a relatively larger proportion of retrieval errors greater than $15 \mathrm{~mm}$ compared to other products; this is illustrated in Fig. 7 using results from the western region in August and the southeastern region in March as examples. Additionally, the overall RMSE of ARC and CMORPH generally fall between those of TAMSAT and TRMM.

Table 4 and Fig. 6 b show that bias ratios in TRMM are generally greater than 1 , indicating overestimation in rainfall amount, while bias ratios in TAMSAT, ARC, and CMORPH indicate rainfall underestimation. Notably, the bias ratio in ARC tends to reach its minimum during June-September, suggesting significant rainfall underestimation in major rainy seasons. Contrastingly, the monthly variation in the bias of CMORPH is more regionally distinctive, fluctuating around 1 in the western region and generally staying below 1 in other regions. Finally, linear correlations in Fig. $6 \mathrm{c}$ are noisy in all products and should be viewed with caution, particularly when the sample size is small.

For evaluating rainfall occurrence, Fig. 8 summarizes monthly skill scores for all products over Oromia, using a threshold of $0 \mathrm{~mm}$ to distinguish between rainy and norain events. A rainy event is identified when the corresponding rainfall is greater than $0 \mathrm{~mm}$; otherwise, it is a no-rain event. A good product performance should have a combination of a high POD, an FB close to the perfect score of 1 , a low FAR, and a high HSS (see section $2 \mathrm{c}$ and Table 3 for definitions).

Over the four climatic regions, all products have best detection (i.e., high POD, low FAR, and FB close to 1) during wet periods. The POD is highest in CMORPH and lowest in ARC, whereas the FAR tends to be very similar in all products. Interestingly, the high POD in 

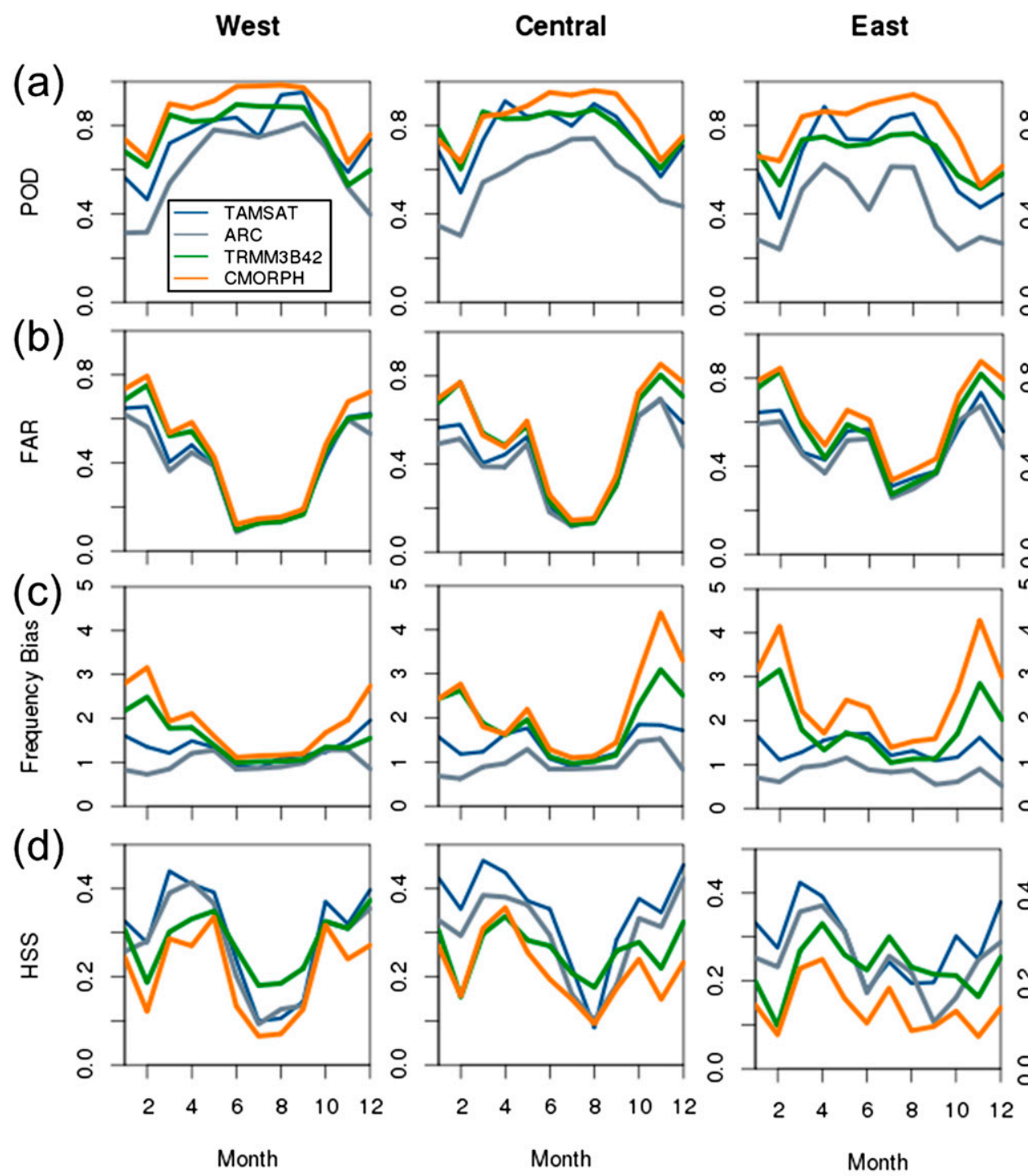

\section{South East}

(a)

(b)

O.

. 
(a)

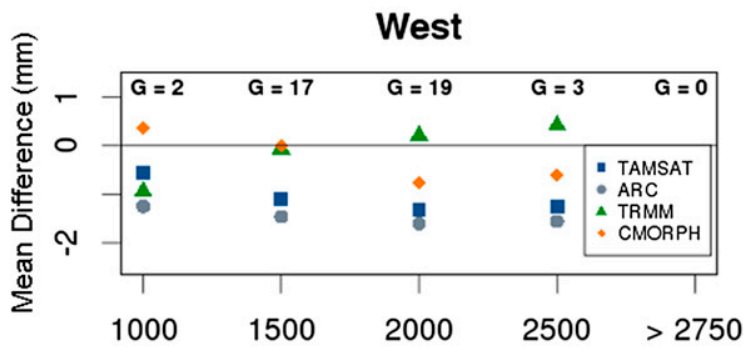

(b)

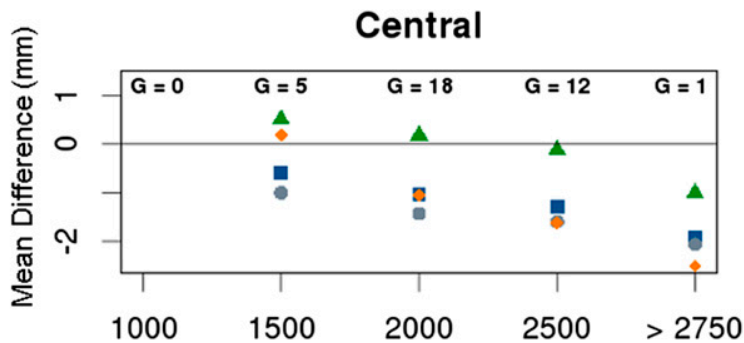

(c)

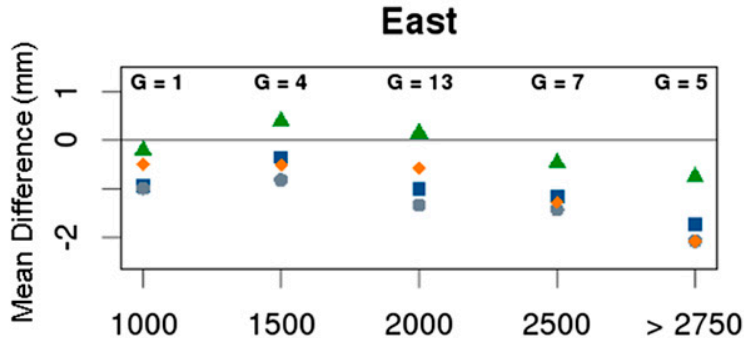

(d)

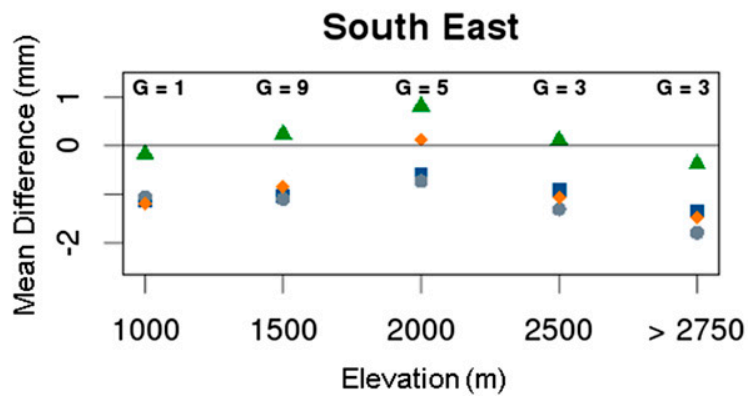

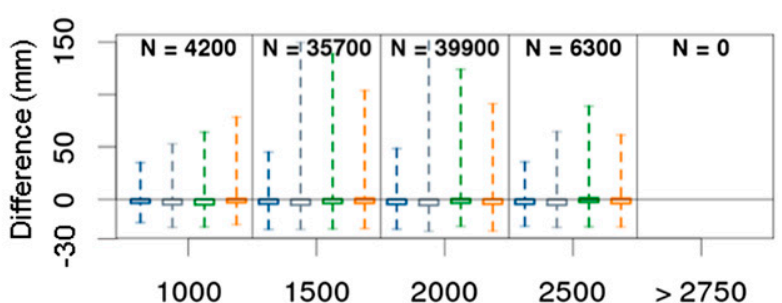
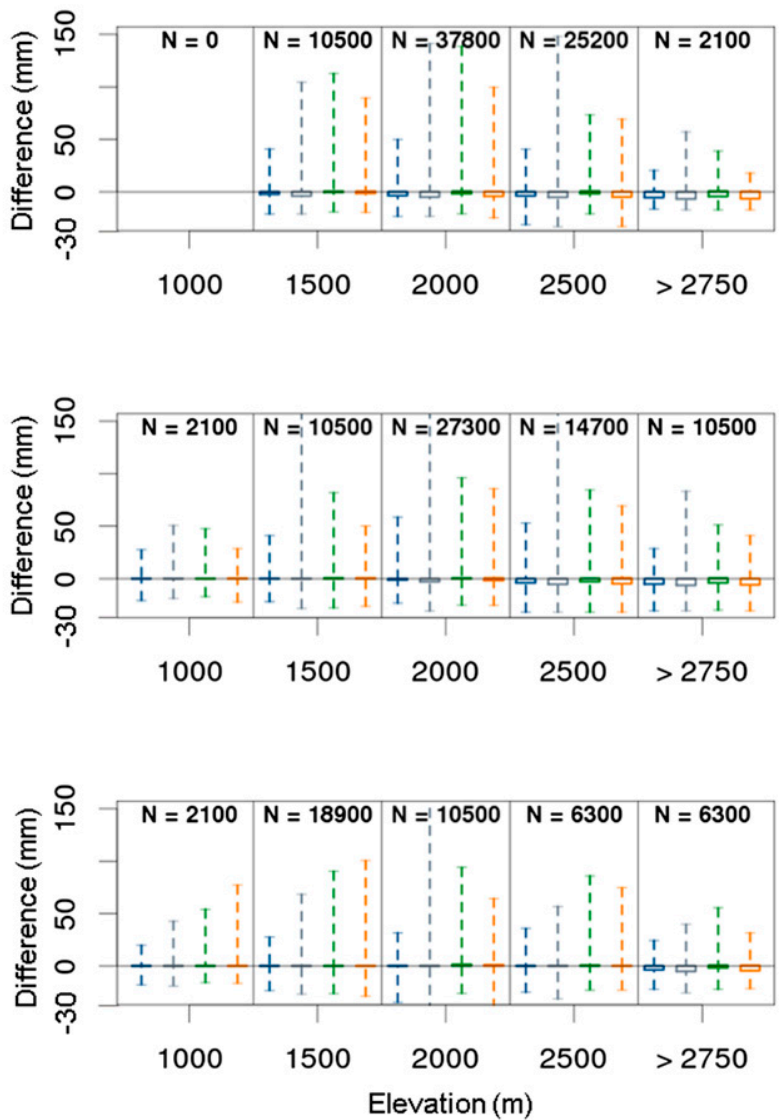

FIG. 9. Difference in daily rainfall $(\mathrm{mm})$ between the satellite-based estimates and gauge observations as a function of elevation during 2002-06. Shown are statistics in Oromia for the (a) western, (b) central, (c) eastern, and (d) southeastern climate regions identified by cluster analysis. A positive difference indicates an overestimate in satellite-based rainfall. (left) The mean differences for each elevation bins; (right) zoomed-in view of the distribution of all data points using box plots. The bottom and top of each box represent the $25 \%$ and $75 \%$ quartiles, respectively. The whiskers mark the min and max rainfall. The letter $G$ represents the number of $0.25^{\circ}$ pixels (containing at least one gauge) used within each elevation bin and $N$ gives the total number of data points used to compute the differences. Note the data points are stratified by five elevation bins, ranging within $\pm 250 \mathrm{~m}$ of the height given by each elevation marker.

that MW-based products yield high POD because of overdetecting rainy events, which lead to lower HSS values in TRMM and CMORPH, particularly in the central and eastern regions in the dry periods.

In summary, in terms of detecting rainy events and capturing the mean rainfall and seasonal variability, TRMM consistently performs the best, although it slightly overdetects rainy events and is associated with larger
RMSE for all regions. On the other hand, TAMSAT has the smallest RMSE and FB values closer to 1, a result of calibrations against rain gauge observations.

\section{c. Impact of topography on rainfall estimates}

To investigate whether errors in rainfall estimates relate to topography, analysis of satellite retrieval error versus elevation over the four subregions is shown in 
TABLE 5. Summary of case studies used for WRF simulations (see section 3c for more detail).

\begin{tabular}{|c|c|c|}
\hline $\begin{array}{l}\text { Description of } \\
\text { discrepancies in satellite } \\
\text { rainfall estimates }\end{array}$ & Date of case & Attributed causes \\
\hline \multirow[t]{2}{*}{$\begin{array}{l}\text { Underestimation in } \\
\text { all products }\end{array}$} & 4 Mar 2002 & $\begin{array}{l}\text { - Low-level shallow precipitating cumulus clouds lacking ice-phase } \\
\text { hydrometeors and associated with relatively warm cloud-top temperatures. }\end{array}$ \\
\hline & 21 Jun 2003 & $\begin{array}{l}\text { - Possible beam-filling effects in MW observations due to localized } \\
\text { convective cells. }\end{array}$ \\
\hline \multirow[t]{2}{*}{$\begin{array}{l}\text { Pronounced overestimation in } \\
\text { MW-based TRMM and } \\
\text { CMORPH products }\end{array}$} & 1 Jun 2002 & $\begin{array}{l}\text { - Frequent deep convection cells with large extent and amount of ice-phase } \\
\text { hydrometeors; retrieval errors likely stem from the assumptions } \\
\text { of ice-phase hydrometeors. }\end{array}$ \\
\hline & 29 Aug 2002 & $\begin{array}{l}\text { - Fast evolving and moving convection cells; it is possible retrieval } \\
\text { errors are caused because gauges provide point measurement and } \\
\text { miss some heavy rainfall. } \\
\text { - Subcloud evaporation is unlikely the main source of retrieval errors } \\
\text { in these cases. }\end{array}$ \\
\hline $\begin{array}{l}\text { Pronounced overestimation } \\
\text { in IR-based TAMSAT and }\end{array}$ & 8 Dec 2003 & $\begin{array}{l}\text { - Prevailing cirrus at upper levels with cold cloud-top temperatures but } \\
\text { negligible surface rainfall. }\end{array}$ \\
\hline
\end{tabular}

31 Mar 2004

Fig. 9. In general, in all but the western region, the mean difference in daily rainfall between retrievals and gauge data becomes more negative with increasing elevation for all products, although TRMM rainfall estimates consistently perform well and agree with rain gauge observations within $1 \mathrm{~mm}$. The increasing magnitude of underestimation with elevation in TAMSAT and ARC is consistent with the findings of Novella and Thiaw (2013) and with another IR-based product (Hirpa et al. 2010; Romilly and Gebremichael 2011). While this conclusion for the IR-based products seems robust, it is slightly complicated for the MW-based products. Regarding rainfall errors at elevations lower than $1500 \mathrm{~m}$, we have found small overestimations in TRMM and CMORPH in certain regions, which is similar to Romilly and Gebremichael (2011). Regarding retrieval errors at elevations higher than $1500 \mathrm{~m}$, the overall increase in retrieval underestimation toward higher elevations in TRMM and particularly CMORPH is consistent with results in Romilly and Gebremichael (2011) and Habib et al. (2012). However, caution should be exercised, because we cannot rule out the possibility that the dependency of rainfall errors on elevation could be due to or partly enhanced by the very small numbers of gauges used in the lowest and highest elevation bins. We should also note that for regions farther north of $10^{\circ} \mathrm{N}$, Romilly and Gebremichael (2011) and Habib et al. (2012) found substantial rainfall overestimations in CMORPH at lower elevations, which unfortunately cannot be confirmed here because of a lack of rain gauge data. These results suggest that the potential overestimations in MW-based products may highly depend on geographic regions and rain gauges used in the analysis, and thus, more observations will be required to help generalize how errors in MW-based rainfall estimates vary with elevation.

Looking in more detail at the errors in rainfall estimates, Fig. 9 (right) shows for all products that approximately $75 \%$ of rainfall estimates are lower than those from gauge data, leading to negative biases in the mean rainfall for most elevations. However, the ranges of rainfall errors are large; $25 \%$ of estimates could be much larger than gauge observations by at least $30 \mathrm{~mm}$. Two mechanisms have been proposed to explain the elevation-dependent biases in satellite estimates over the Ethiopian highlands. For overestimations at lower elevations, one hypothesis is subcloud evaporation of rainfall before it reaches the surface in a dry lower atmosphere, where precipitating clouds with ice-phase hydrometeors aloft produce cold cloud-top temperatures in IR channels and a strong scattering signature in MW observations, which lead to higher rainfall estimates compared to surface measurements (McCollum et al. 2000; Dinku et al. 2011). For underestimations at higher elevations, one hypothesis is that shallow convection along mountain slopes lacks suspended ice hydrometeors, leading to warmer cloud-top temperatures and a weaker MW scattering signal, which in turn cannot capture heavy rainfall events at the surface (Habib et al. 2012).

To test these hypotheses and investigate how the satellite retrieval discrepancies relate to precipitation characteristics influenced by topography, we use WRF simulations to investigate a number of cases, grouped by 1) rainfall underestimation in all products; 2) pronounced overestimation in MW-based products; and 3) pronounced overestimation in IR-based products, as 


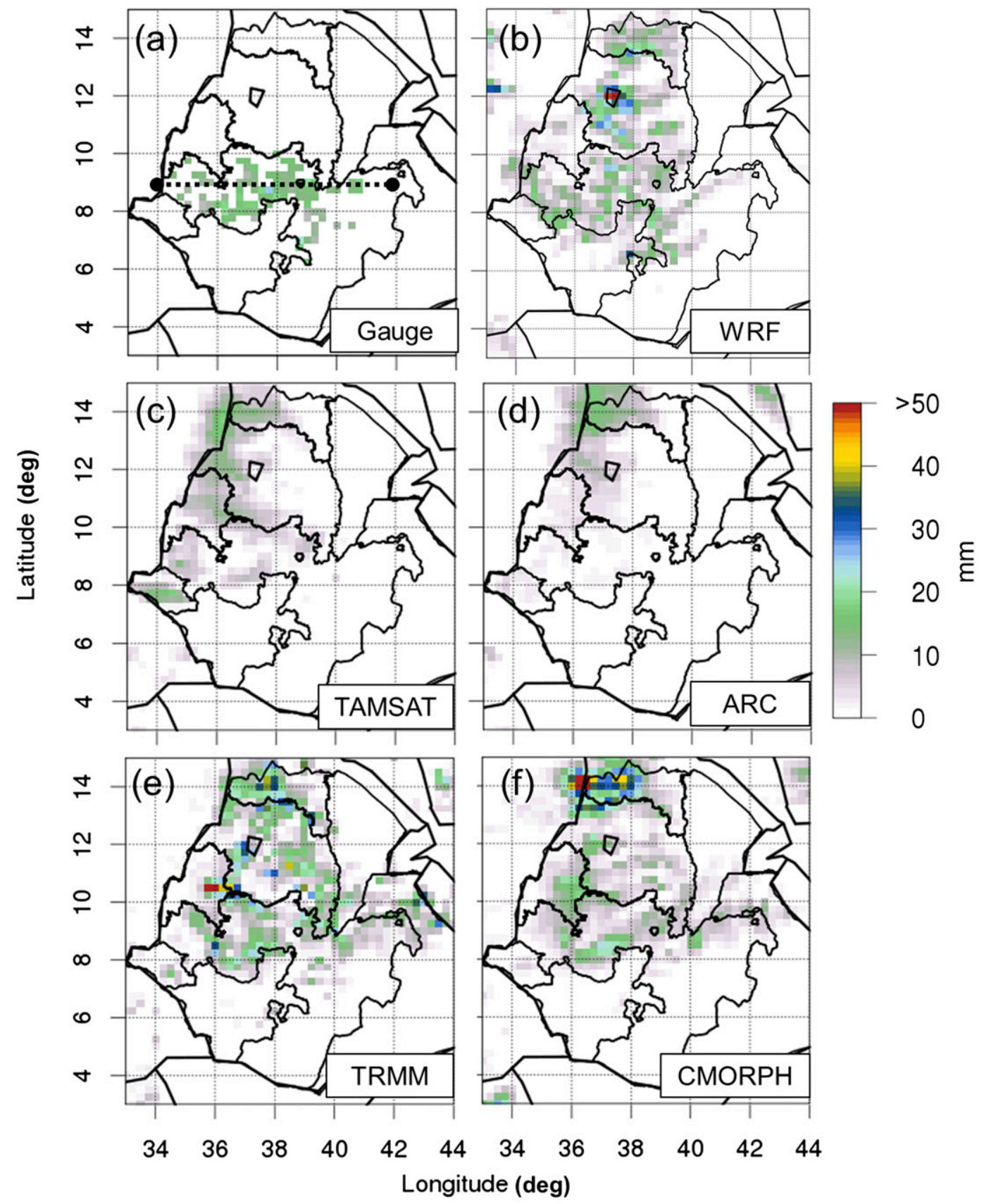

FIG. 10. Maps of 24-h accumulated rainfall (mm) from (a) rain gauges, (b) WRF simulations, (c) TAMSAT, (d) ARC, (e) TRMM 3B42, and (f) CMORPH, starting at 0600 UTC 21 Jun 2003. In (a), the black dashed line along $9^{\circ} \mathrm{N}$ marks the cross section used to investigate the relationship between satellite-gauge discrepancy and vertical hydrometeor structure in Figs. 11 and 12.

detailed in Table 5. WRF provides detailed horizontal and vertical structures of cloud water, cloud ice, rain, snow, and graupel, which play different roles in IR and MW observations. Note that the structures and amount of hydrometeors are sensitive to the microphysics scheme employed in simulations; however, testing this sensitivity is out of the scope of this paper.
For the IR-based TAMSAT and ARC, we focus on whether cloud tops reach cold cloud temperature thresholds (typically below $-20^{\circ} \mathrm{C}$ ) so rainfall can be appropriately retrieved (see section 2). IR-based retrieval methods tend not to perform well for warm precipitating clouds and will overestimate rainfall in the presence of cirrus (Todd et al. 1995; Dinku et al. 2011). 
For MW-based methods, surface rainfall over land is retrieved primarily based on the scattering signal by large particles; thus, we focus on evaluations of rain, snow, and graupel amounts during a day. Since scattering by hydrometeors greatly depends on the refraction index and size distributions of particles (Bennartz and Petty 2001; Johnson et al. 2012), it is difficult to relate modeled hydrometeor amounts directly to satellite brightness temperatures and surface rainfall without extensively evaluating the representativeness of these assumptions and treatments. For interpretation purposes, we use a simple radiative transfer model (Han et al. 2010) to interpret modeled hydrometeor amounts qualitatively. For example, graupel content of $0.1 \mathrm{~g} \mathrm{~m}^{-3}$ for a graupel layer of $3 \mathrm{~km}$ could lead to radar reflectivity of 20-30 dBZ (depending on particle size distribution). Snow content of $0.6 \mathrm{~g} \mathrm{~m}^{-3}$ for a snow layer of $4 \mathrm{~km}$ could lead to radar reflectivity of $20-35 \mathrm{dBZ}$. Hydrometeors exceeding these amounts are associated with a scattering index at $85 \mathrm{GHz}$ greater than 20 (Han et al. 2010), producing sufficient scattering signal, and should be detected by MW-based retrieval methods.

\section{1) UNDERESTIMATION IN ALL PRODUCTS}

This section focuses on examples where rainfall underestimation occurs in all products. Figure 10 shows

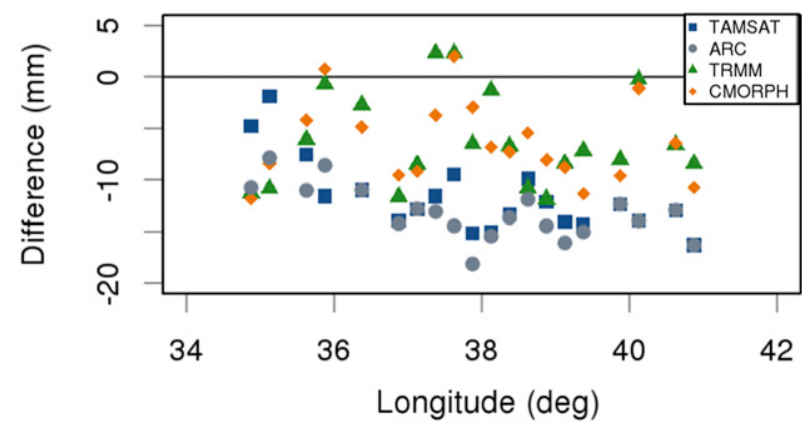

FIG. 11. Mean differences in surface daily rainfall ( $\mathrm{mm})$ between rain gauge measurements and satellite retrievals on 21 Jun 2003 along the $9^{\circ} \mathrm{N} \pm 0.5^{\circ}$ zonal cross section. A negative difference indicates an underestimation in rain-rate retrievals.

an example on 21 June 2003, when daily rainfall from rain gauges ranges between 5 and $20 \mathrm{~mm}$. Compared to rain gauges, WRF successfully simulates the magnitude and spatial distribution of surface precipitation. The simulated rainfall distribution extending from north to south of the domain is clearly captured by TRMM and CMORPH; on the other hand, TAMSAT and ARC products miss a lot of surface precipitation. Note that precipitation seen in satellite products and WRF simulations in the north of the Oromia region was not shown in Fig. 10a because of a lack of rain gauges.
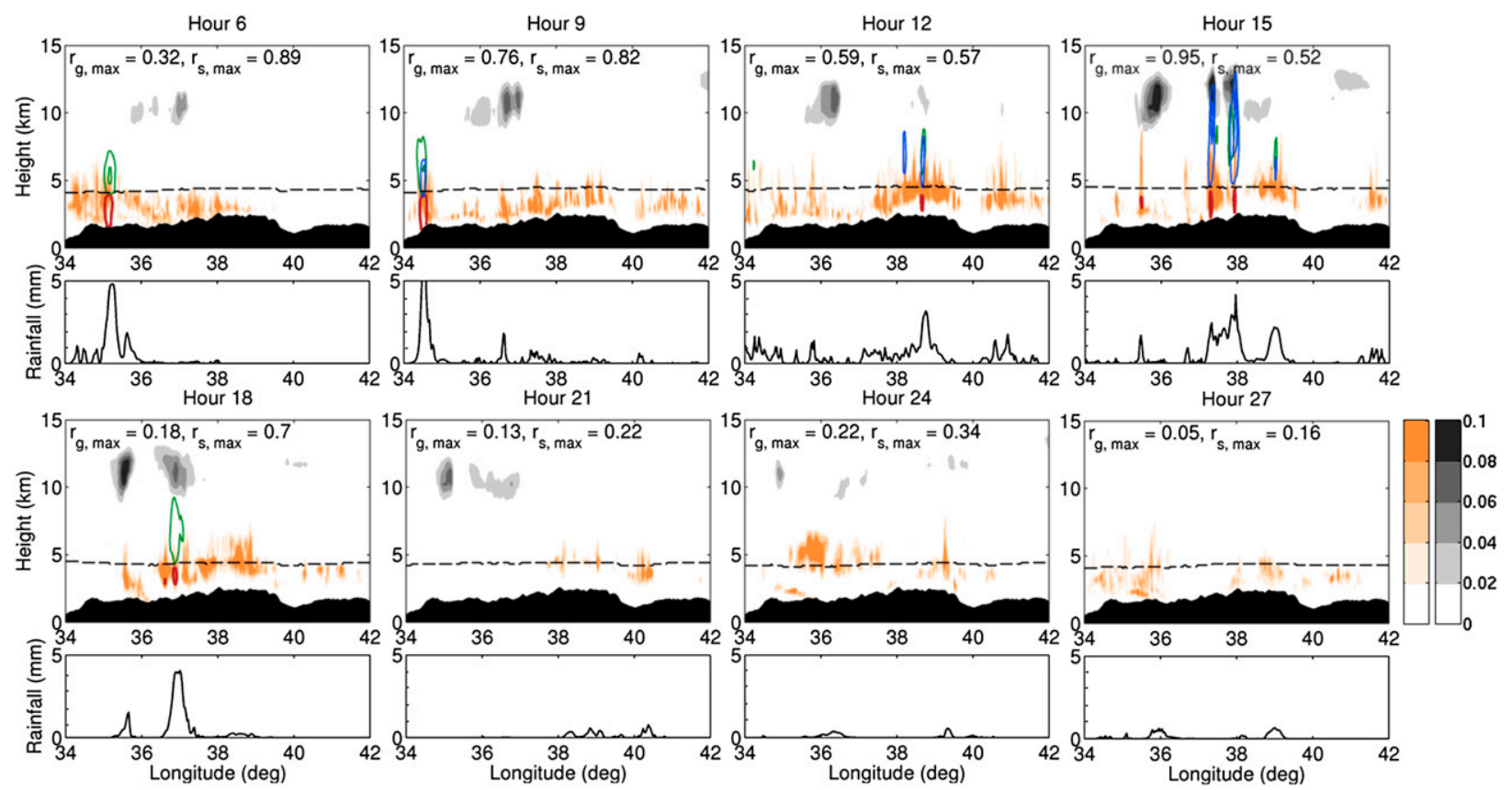

FIG. 12. Vertical cross sections and corresponding estimated rainfall (mm) from WRF every $3 \mathrm{~h}$ from 0600 UTC 21 Jun to 0300 UTC 22 Jun 2003 along the $9^{\circ} \mathrm{N} \pm 0.5^{\circ}$ zonal cross section. Filled contours represent ice (gray) and cloud water (orange) content $\left(\mathrm{g} \mathrm{kg}^{-1}\right)$. Colored contours represent contoured mixing ratios $\left(\mathrm{g} \mathrm{kg}^{-1}\right)$ for graupel (blue) and snow (green) at intervals of $0.4,0.8,1.2$, and $1.6 \mathrm{~g} \mathrm{~kg}^{-1}$ and for rainwater (red) at $0.2 \mathrm{~g} \mathrm{~kg}^{-1}$. The dashed line represents the freezing-level height. The max mixing ratios ( $\left.\mathrm{g} \mathrm{kg}^{-1}\right)$ of graupel $g$ and snow $s$ within each cross section are given by $r_{g \text {,max }}$ and $r_{s, \text { max }}$, respectively. 

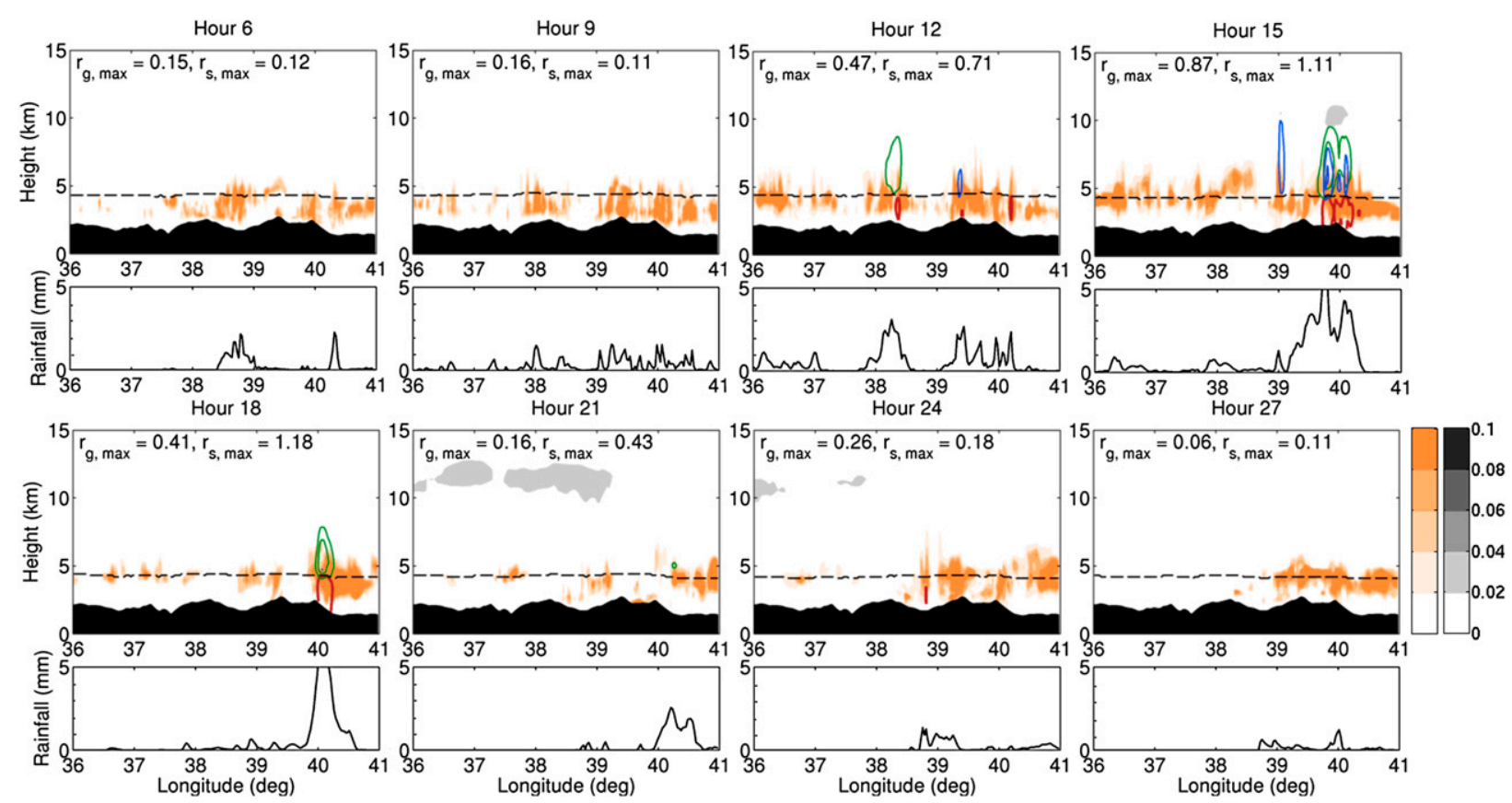

FIG. 13. As in Fig. 12, but for the case on 4 Mar 2002 given an $8^{\circ} \mathrm{N} \pm 0.5^{\circ}$ zonal cross section.

To examine plausible links between elevation and rainfall retrieval errors, we zoom in on a particular zonal cross section along $9^{\circ} \mathrm{N} \pm 0.5^{\circ}$. This zonal section was chosen because of the varied topography and the relatively dense distribution of rain gauges and because it was the area where all products significantly underestimated gauge rainfall. Averaging rainfall and hydrometeor profiles over a given zonal cross section also helps to minimize the impact of the collocation issue between the gauges, satellite estimates, and model outputs. As Fig. 11 shows, the rainfall underestimations along this particular cross section in MW- and IR-based products are up to 10 and $20 \mathrm{~mm}$, respectively. For TAMSAT and ARC, the retrieval errors tend to be smaller at elevations lower than $2000 \mathrm{~m}$ (i.e., in the west of $36^{\circ} \mathrm{E}$ ) than those at higher elevations, but this elevation dependence is not evident in TRMM and CMORPH products.

Vertical profiles of hydrometeors in Fig. 12 suggest surface precipitation is introduced by frequent shallow precipitating clouds and occasional deep yet short-lived convection cells in the afternoon and evening (09001500 UTC). Throughout the day, the shallow clouds have cloud-top heights only about $1 \mathrm{~km}$ above the freezing level, which likely leads to rainfall underestimated by the IR-based TAMSAT and ARC products. Meanwhile, cirrus clouds are frequent, but their coverage is not overwhelming, which does not help offset retrieval errors in the IR-based products. In addition, the convective cells in the afternoon contain sufficient graupel contents up to $0.95 \mathrm{~g} \mathrm{~kg}^{-1}$, producing cold cloud-top temperatures and detectable brightness temperature depression at higher MW frequencies; therefore, we expect that all products are capable of retrieving some rainfall from such convective systems. However, whether satellites would capture these systems depends on their overpass time. In addition, many of the individual convection cells are narrow and some of them may cover an area smaller than the nominal footprint of microwave sensors (e.g., TMI; Kummerow et al. 2001; Olson et al. 2006). The beam-filling effect due to these narrow and localized convection cells may lead to rainfall underestimated by TRMM and CMORPH.

Simulations for another case on 4 March 2002 have also suggested prevalent shallow and relatively warm precipitating clouds are likely the main cause for rainfall underestimation in all products (as shown in Fig. 13). This agrees with the hypothesis that satellite underestimation is caused by shallow convection with a warm signal, suggested by Habib et al. (2012).

\section{2) Pronounced overestimation IN MW-BASED PRODUCTS}

We further examine cases with pronounced overestimations in MW-based TRMM and CMORPH rainfall estimates. Figure 14 shows an example on 1 June 2002 when daily rainfall from rain gauges ranges between 5 and $20 \mathrm{~mm}$; IR-based TAMSAT and ARC products agree with rain gauge observations reasonably well, but TRMM and CMORPH significantly overestimate 24-h accumulated rainfall. Along the zonal cross section at 


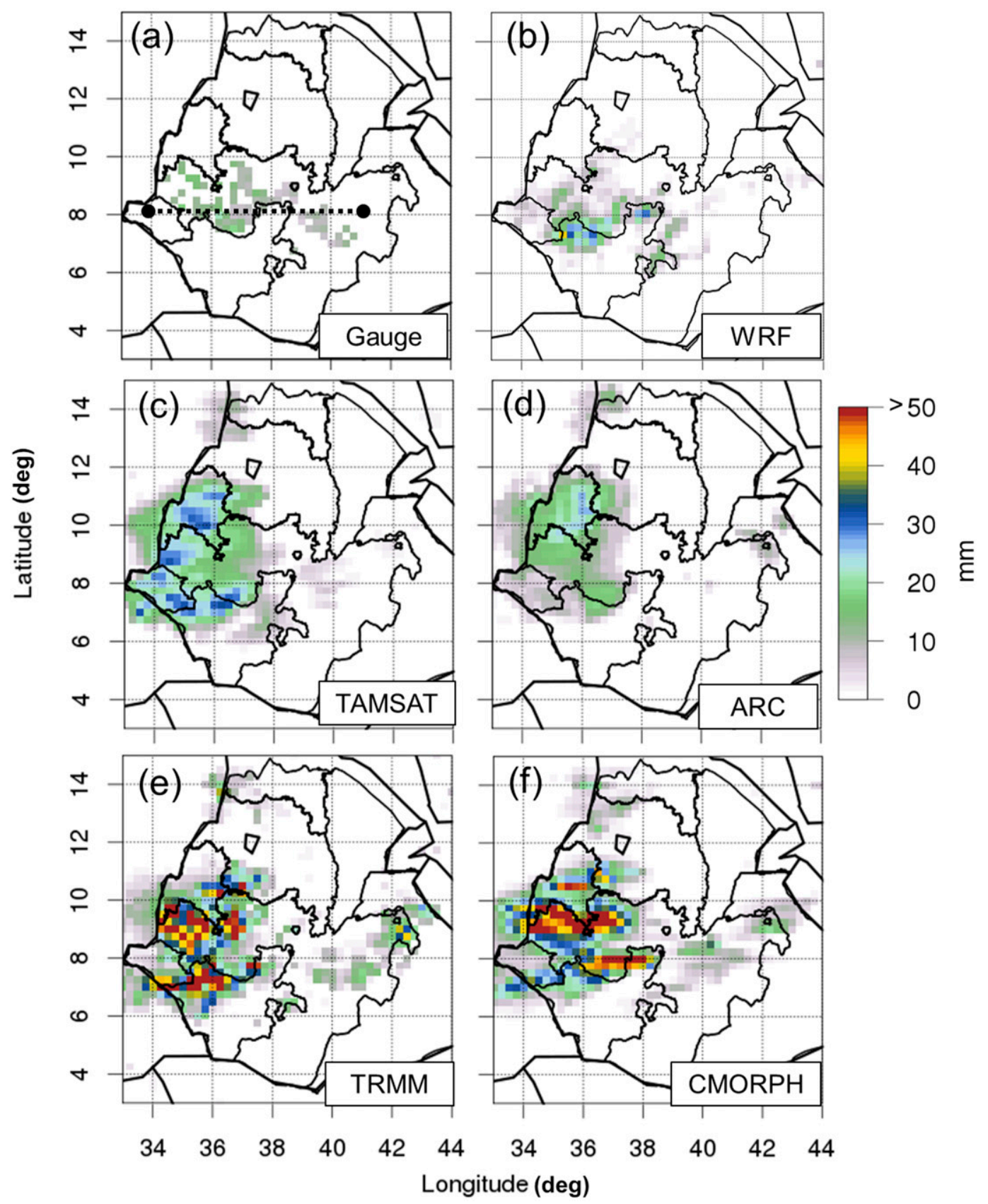

FIG. 14. As in Fig. 10, but for the case starting at 0600 UTC 1 Jun 2002. In (a), the dashed line along $8^{\circ} \mathrm{N}$ marks the cross section used to investigate the relationship between satellite-gauge discrepancy and vertical hydrometeor structure in Figs. 15 and 16.

$8^{\circ} \mathrm{N} \pm 0.5^{\circ}$, Fig. 15 shows that TRMM and CMORPH tend to overestimate daily rainfall by at least $10 \mathrm{~mm}$ west of $38^{\circ} \mathrm{E}$ at elevations of $1000-2000 \mathrm{~m}$, while the retrieval errors are much smaller east of $38^{\circ} \mathrm{E}$ above $2500 \mathrm{~m}$. The discrepancies over these regions are consistent with the general relationships illustrated in Fig. 9; this shows that the satellite products are more susceptible to large rainfall overestimations at $1000-2000 \mathrm{~m}$ in contrast to higher levels above $2500 \mathrm{~m}$, although recall that the number of gauges located at higher elevations is much smaller than at $1000-2000 \mathrm{~m}$.

For this case, WRF simulations have a remarkable resemblance with rain gauge observations in both spatial distribution and magnitude (as shown in Fig. 14). 


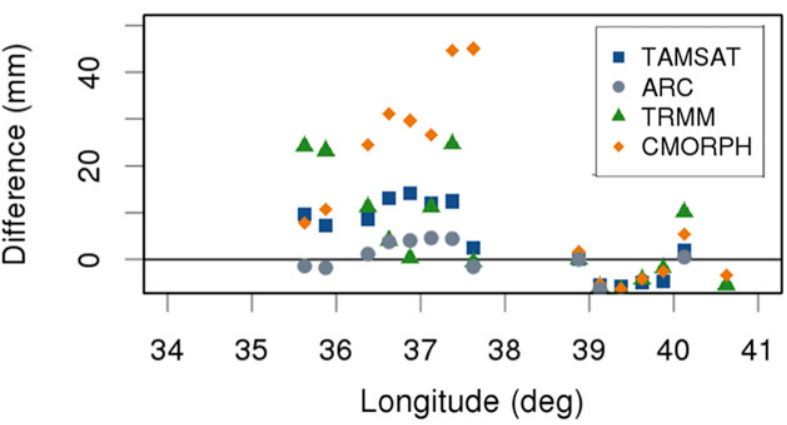

FIG. 15. As in Fig. 11, but for the case on 1 Jun 2002, given an $8^{\circ} \mathrm{N} \pm$ $0.5^{\circ}$ zonal cross section. A positive difference indicates an overestimation in rain-rate retrievals.

Overall, simulations along $8^{\circ} \mathrm{N} \pm 0.5^{\circ}$ in Fig. 16 show that a few warm, shallow cumulus clouds pop out east of $38^{\circ} \mathrm{E}$ with light surface precipitation at local noon (0900 UTC). These clouds are associated with warm cloud-top temperatures and lack ice-phase hydrometers, making it challenging for both IR- and MW-based methods to retrieve rainfall, which may explain the slight underestimation in all products east of $38^{\circ} \mathrm{E}$, as shown in Fig. 15. During the afternoon and evening, deeper and more active convection cells form mainly west of $38^{\circ} \mathrm{E}$ over elevated peaks with substantial surface precipitation, overlying anvil cirrus and intensive graupel contents ranging between 0.4 and $2.1 \mathrm{~g} \mathrm{~kg}^{-1}$. These convection cells move out of the zonal cross section toward the southwest and dissipate at night by 2200 UTC.
Similar evolutions of clouds and precipitation are found in another case on 29 August 2002. As shown in Fig. 17, large daily rainfall overestimations occur in TRMM and $\mathrm{CMORPH}$ to the west of $38^{\circ} \mathrm{E}$. The corresponding vertical profiles of hydrometeors from WRF simulations in Fig. 18 again reveal morning shallow, warm clouds along $8^{\circ} \mathrm{N} \pm$ $0.5^{\circ}$ and deep convective clouds in the afternoon and evening with significant ice-phase hydrometeors and surface precipitation, particularly west of $38^{\circ} \mathrm{E}$.

A number of factors are examined to provide plausible explanations for rainfall overestimated by TRMM and CMORPH. First, the deep convective clouds have large horizontal and vertical extent. We expect that MW-based satellite products perform well for such convective systems, because the scattering from hydrometeors should be strong and sufficient. However, this cannot rule out the source of errors introduced by inappropriate assumptions of hydrometeors, which in some cases can lead to variations in the scattering index of as much as $50 \mathrm{~K}$ for the same rain rate (Bennartz and Petty 2001). In addition, Tompkins and Adebiyi (2012) found that CMORPH retrieval errors could be enhanced by cirrus, which was prevalent in our simulations and may explain the larger bias found in CMORPH than in TRMM. Note that these rainfall overestimations in TRMM and CMORPH may be offset to some extent by frequent shallow precipitating cumulus shown in Figs. 16 and 18.

Second, subcloud evaporation processes have been used to explain rainfall overestimation at low elevations in northeastern Ethiopia where the low-level relative
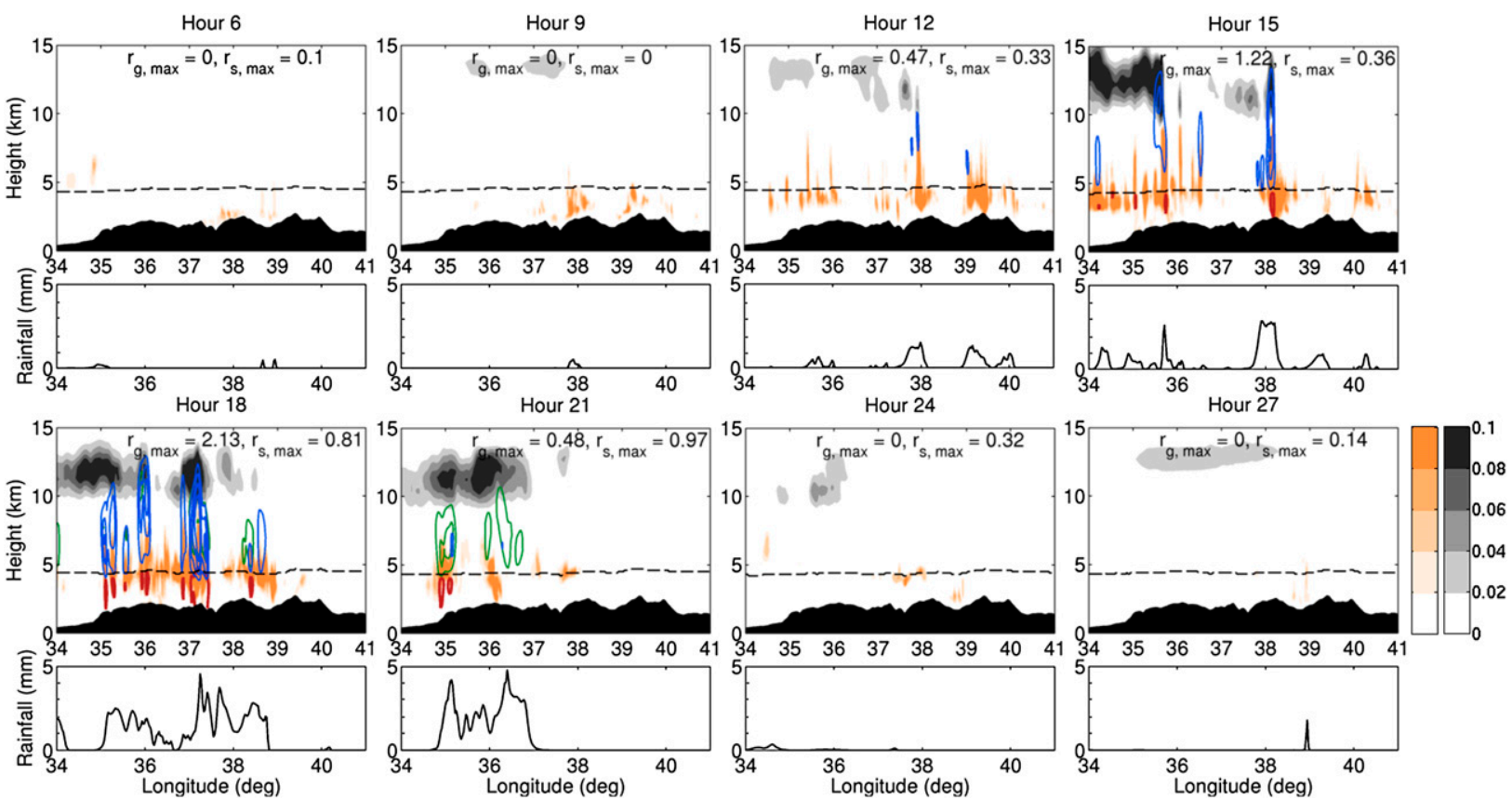

FIG. 16. As in Fig. 12, but for the case on 1 Jun 2002 given an $8^{\circ} \mathrm{N} \pm 0.5^{\circ}$ zonal cross section. 


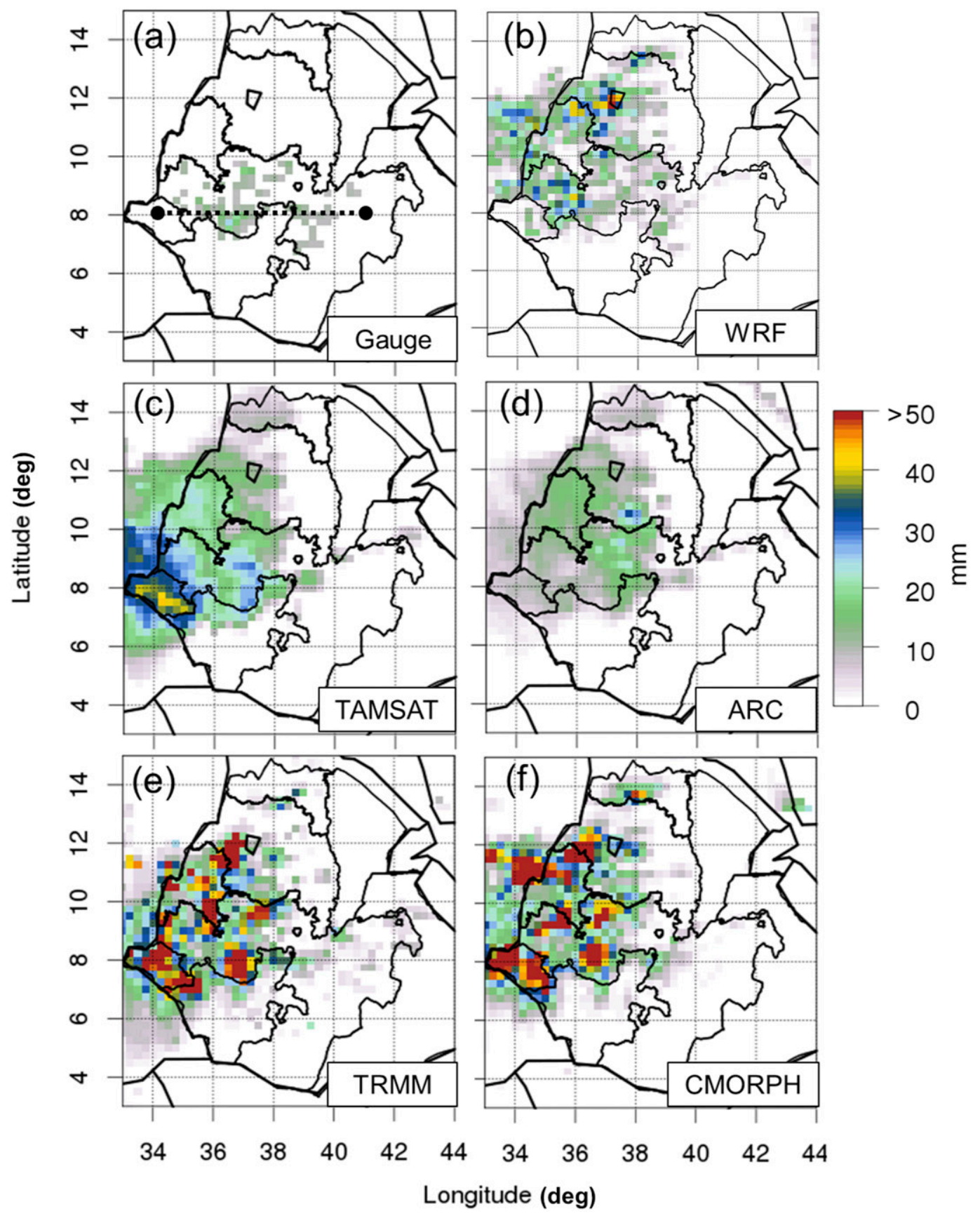

FIG. 17. As in Fig. 10, but for the case starting at 0600 UTC 29 Aug 2002. In (a), the dashed line along $8^{\circ} \mathrm{N}$ marks the cross section used in Fig. 18.

humidity is $50 \%$ (Dinku et al. 2011). However, over Oromia we have found that the mean low-level relative humidity is around $80 \%$ and thus subcloud evaporation is unlikely to be an important contributor to satellite rainfall overestimations in these cases.

Third, we must consider the possibility that rain gauges provide point measurements and errors between gauge observations and satellite retrievals can be enhanced when precipitation systems evolve and move fast, as shown in these cases.

\section{3) Pronounced overestimation In IR-BASED PRODUCTS}

Finally, we examine cases with pronounced overestimation in IR-based satellite rainfall estimates. Figure 19 displays one example in which low daily 

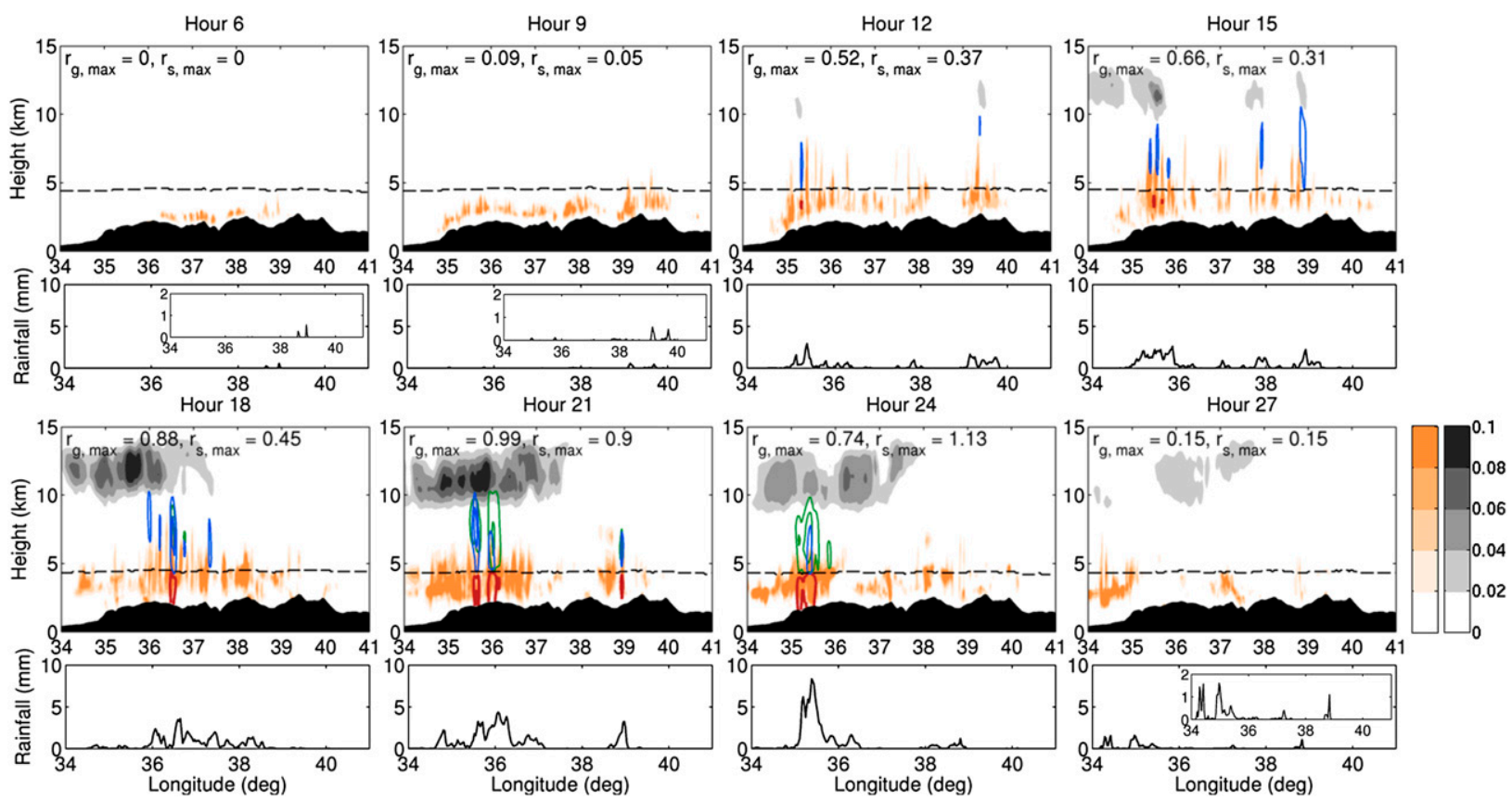

FIG. 18. As in Fig. 12, but for the case on 29 Aug 2002, given an $8^{\circ} \mathrm{N} \pm 0.5^{\circ}$ zonal cross section.

rainfall is observed by rain gauges, but IR-based TAMSAT and ARC estimates are generally greater than $10 \mathrm{~mm}$; these overestimations are even more evident in ARC in the region between $9^{\circ}$ and $10^{\circ} \mathrm{N}$. Overall, the overestimation in TAMSAT and ARC along a zonal cross section of $8^{\circ} \mathrm{N} \pm 0.5^{\circ}$ is about $10-20 \mathrm{~mm}$, but the overestimation appears to be elevation invariant (figures not shown). For this case on 31 March 2004, WRF simulations indicate light precipitation located at $6^{\circ}-$ $8^{\circ} \mathrm{N}$; the rainfall in the eastern part of $38^{\circ} \mathrm{E}$ agrees with rain gauge observations, but unfortunately, we cannot draw any conclusions for the western part because of a lack of rain gauge measurements.

Unlike the cases in the previous subsections, WRF simulations along $8^{\circ} \mathrm{N} \pm 0.5^{\circ}$ in Fig. 20 clearly demonstrate the presence of thick cirrus clouds aloft at altitudes of $10-15 \mathrm{~km}$ throughout the entire day and the presence of low-level warm clouds with light rainfall mainly in the afternoon. The thick cirrus clouds with sustained duration and negligible surface precipitation below will register cold cloud-top temperatures in IR observations, leading to overestimations in IR-based rainfall estimates. Additionally, these clouds lack graupel and snow particles, and thus, MW-based TRMM and CMORPH products do not detect any rainfall, consistent with Figs. 19e and 19f.

Similarly, for the case on 8 December 2003 (Fig. 21), graupel and snow are absent in this 24-h simulation. Low-level warm clouds are seen through the entire day, particularly around $7^{\circ}-9^{\circ} \mathrm{N}$ over elevated peaks, while extensive cirrus forms at $9-12 \mathrm{~km}$ from 1500 (local evening) to 2200 UTC (after midnight). The prevailing cirrus with cold cloud-top temperatures likely causes rainfall overestimations in IR-based products, consistent with the finding in the previous case on 31 March 2004.

\section{Summary and conclusions}

We have evaluated daily rainfall retrievals from TAMSAT, ARC, TRMM, and CMORPH over the Ethiopian highlands and investigated the effects of varying topography on the retrievals. The assessment used dense rain gauge measurements over the Oromia region in Ethiopia during 2002-06 and was conducted for four climatic subregions that have distinct annual cycles of rainfall. The intercomparison between satellite products and gauge data reveals that TRMM captures the annual cycles well, while the other three products underestimate the magnitude of the rainfall peak during rainy seasons. Additionally, TAMSAT has the smallest RMSE, attributed to the fact that TAMSAT is calibrated locally to the rain gauge observations. Regarding rainfall frequency of occurrence, all products demonstrate their best ability to detect rainy events in wet seasons but overdetect rainy events, particularly during dry seasons and in MW-based TRMM and CMORPH products.

Capitalizing on the highly varying nature of the topography over Oromia, the impacts of elevation on the satellite rainfall estimates are investigated. Overall, TAMSAT, ARC, and CMORPH show an increased 

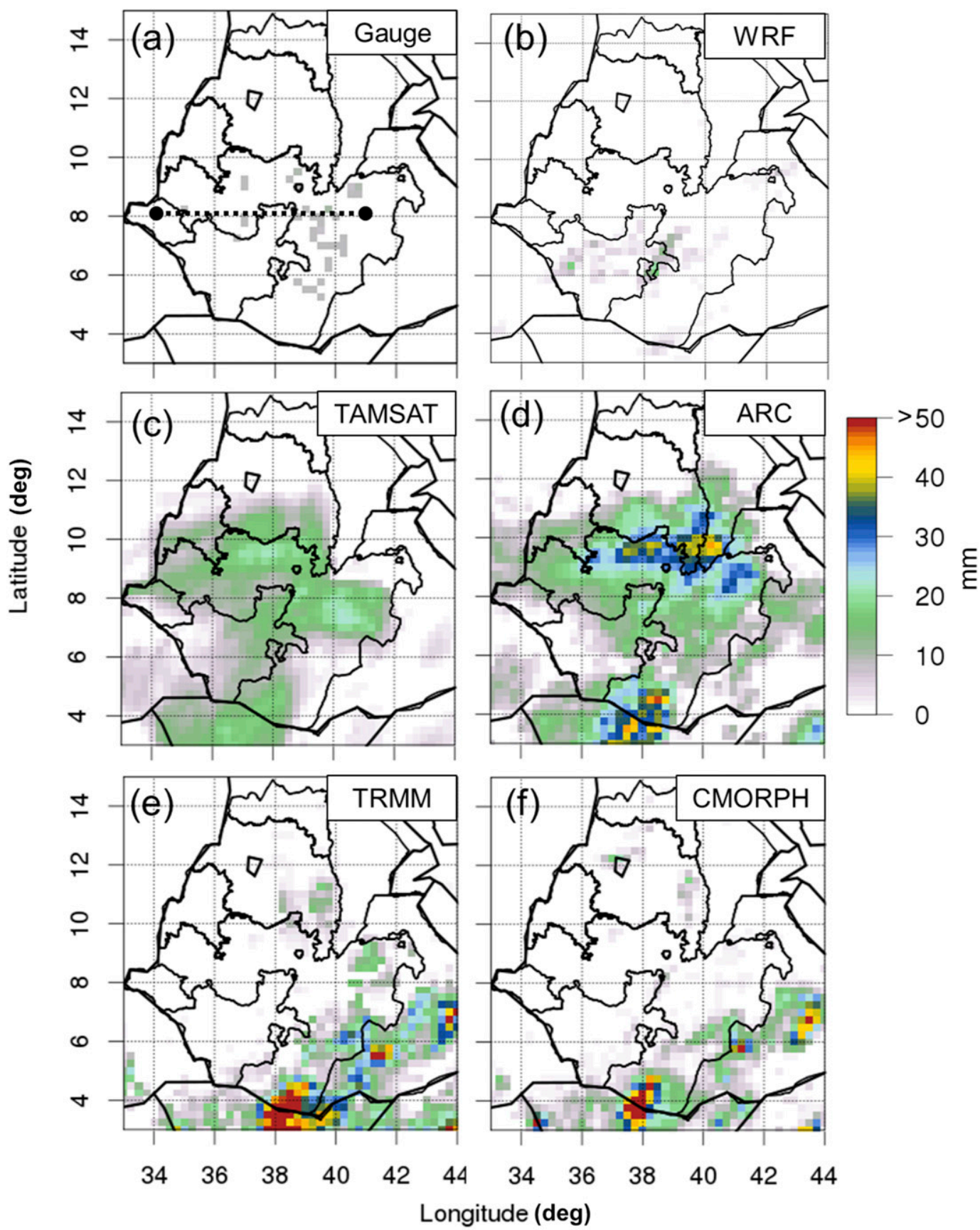

FIG. 19. As in Fig. 10, but for the case starting at 0600 UTC 31 Mar 2004. In (a), the dashed line along $8^{\circ} \mathrm{N}$ marks the cross section used in Fig. 20.

magnitude of underestimation with increasing elevation. TRMM, on the other hand, displays smaller mean differences against the gauge data, although it also underestimates rainfall over the highest terrain similar to other products. However, we need to bear in mind the number of gauges available for the lowest and highest terrain are small, and thus, more gauges are necessary to enhance the statistical meaning of the elevation impact. It is also important to note that concentrating only on the mean retrieval errors can be misleading, as $25 \%$ of rainfall estimates could be overestimated and much larger than gauge observations by at least $30 \mathrm{~mm}$ at all elevations. To explore the causes of under- and overestimation in rainfall retrievals, we analyzed detailed vertical structures of hydrometeors using WRF simulations for cases with 1) rainfall underestimation in all products, 2) pronounced 

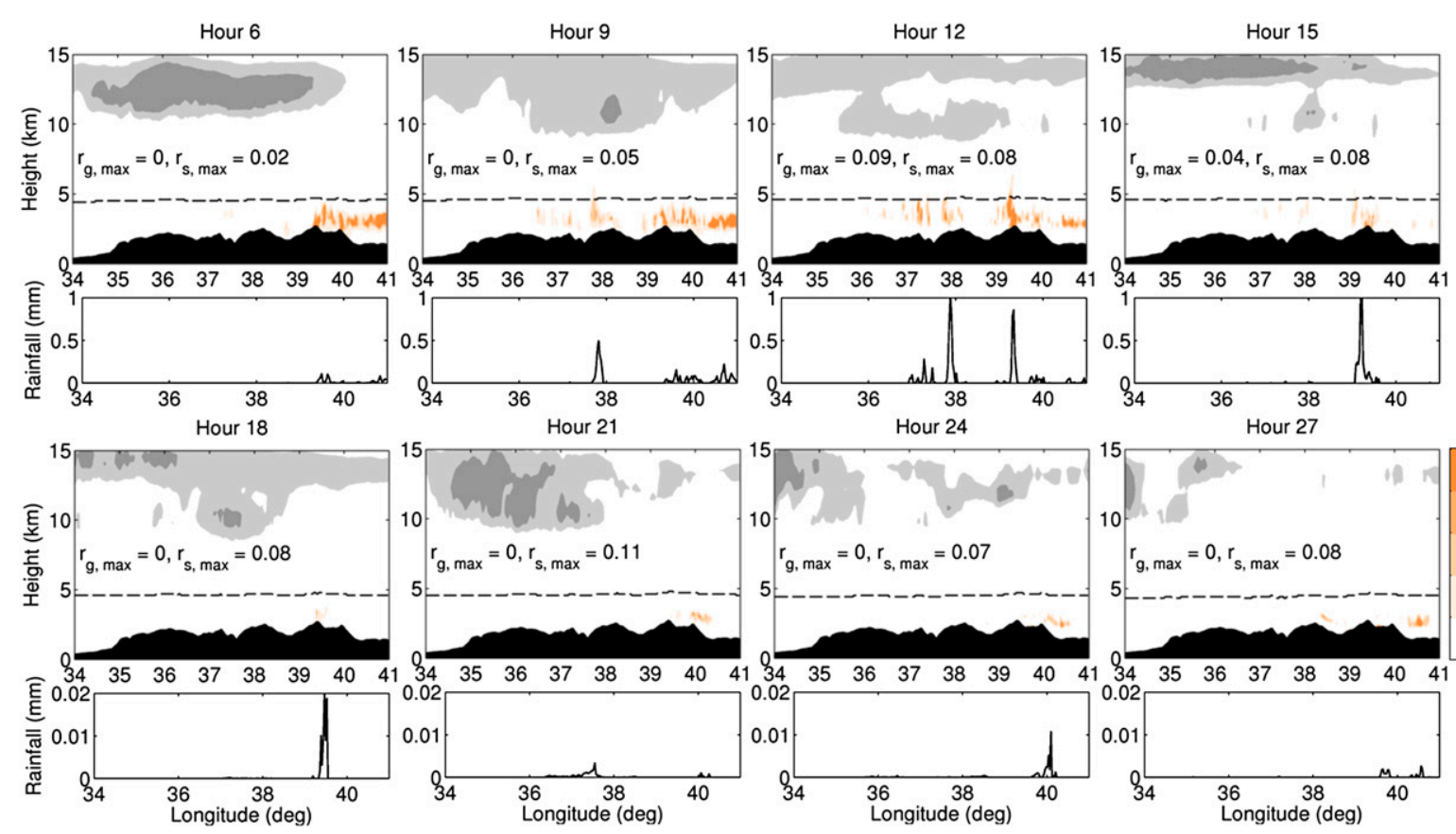

FIG. 20. As in Fig. 12, but for the case on 31 Mar 2004, given an $8^{\circ} \mathrm{N} \pm 0.5^{\circ}$ zonal cross section. Note the rainfall range changes.

overestimation in MW-based products, and 3) pronounced overestimation in IR-based products. Key findings are summarized as follows.

First, WRF simulations show an encouraging agreement with gauge observations in the magnitude and spatial distribution of surface precipitation. For cases with rainfall underestimated by all products, warm shallow precipitating clouds dominate. These clouds lack cold cloud-top temperatures and thus will not be detected by IR-based retrieval algorithms (TAMSAT and ARC),
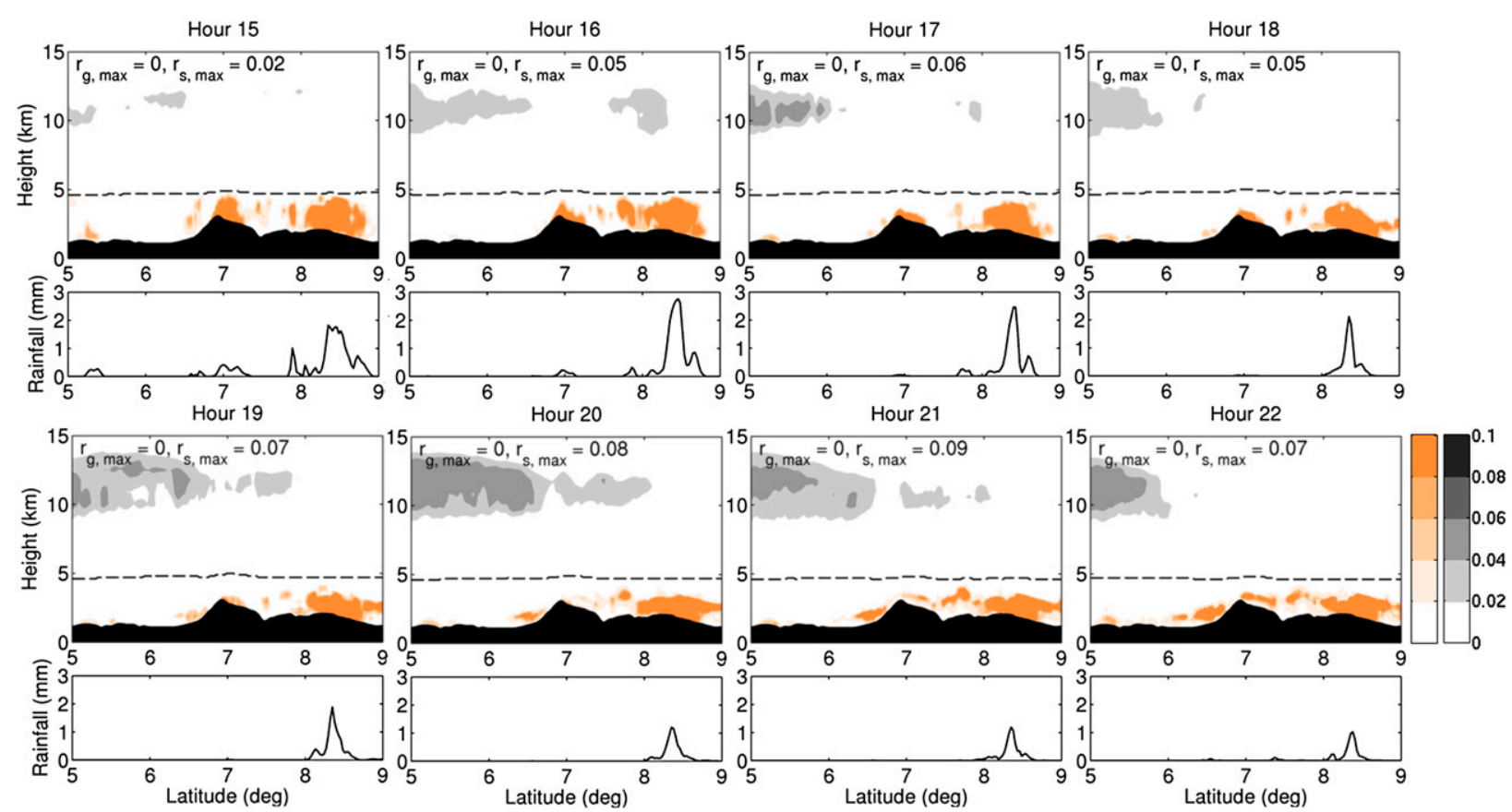

FIG. 21. As in Fig. 12, but for every hour from 1500 to $2200 \mathrm{UTC}$ during the case on $8 \mathrm{Dec} 2003$, given a $40^{\circ} \mathrm{E} \pm 0.5^{\circ}$ meridional cross section. 
leading to a rainfall underestimation. Similarly, MW-based algorithms (TRMM and CMORPH) will miss this warm rain because of a lack of ice-phase hydrometeors.

Second, for cases with overestimation in MW-based TRMM and CMORPH products, fast evolving and advecting deep convective cells dominate. Since these cells are associated with a significantly larger extent and amount of graupel and cloud ice than other cases, one of the potential causes for rainfall overestimation could be that the assumptions of ice-phase hydrometeors in algorithms may not work particularly well over the Oromia region. Another plausible cause is that rain gauges provide point measurements and are unable to capture all heavy rainfall events.

Third, simulations reveal the overestimation in IRbased TAMSAT and ARC products is due to prevailing nonprecipitating cirrus associated with cold cloud-top temperatures, as seen in previous studies (e.g., Adler and Negri 1988; Todd et al. 1995, 1999). Note that since the Oromia rain gauges are mainly distributed across the Ethiopian highland area, which tends to have higher relative humidity than the northeastern part of the country, we were unable to properly test the hypothesis that subcloud evaporation leads to overestimation in satellite rainfall retrievals.

The results of this work emphasize that daily satellite rainfall estimates from TAMSAT and other satellite products perform reasonably well over a challenging region dominated by highly varying topography, but retrieval errors are highly regional and subject to complex precipitation processes. The study also highlights the potential benefits of using high-resolution mesoscale simulations to give insights into satellite retrieval errors over complex terrain, although it is important to note that the structures and amount of hydrometeors are sensitive to the microphysics scheme employed in simulations and that improving microphysics schemes remain an active research area. Additionally, this analysis will help future improvements of the TAMSAT algorithm with a scope to increasing the reliability of rainfall estimates over Ethiopia.

Acknowledgments. This work was funded by a NERC (Natural Environment Research Council) Ph.D. Studentship. The authors thank the Ethiopian Meteorological Agency for providing the Oromia rain gauge data; Helen Greatrex for the software used to interpolate the rain gauge data; and the TAMSAT group at the University of Reading for providing the daily rainfall estimates, the development of which has been supported by a NERC Ph.D. Studentship held by Ross Maidment and CIAT-CCAFS Partner Subagreement C-148-11 between TAMSAT and the IRI (International Research
Institute for Climate and Society). We also thank the three anonymous reviewers whose comments greatly helped to improve this manuscript.

\section{REFERENCES}

Adler, R. F., and J. A. Negri, 1988: A satellite infrared technique to estimate tropical convective and stratiform rainfall. J. Appl. Meteor., 27, 30-51, doi:10.1175/1520-0450(1988)027<0030: ASITTE $>2.0 . \mathrm{CO} ; 2$.

Arkin, P. A., and B. N. Meisner, 1987: The relationship between large-scale convective rainfall and cold cloud over the Western Hemisphere during 1982-84. Mon. Wea. Rev., 115, 51-74, doi:10.1175/1520-0493(1987)115<0051:TRBLSC > 2.0.CO;2.

Barancourt, C., J. D. Creutin, and J. Rivoirard, 1992: A method for delineating and estimating rainfall fields. Water Resour. Res., 28, 1133-1144, doi:10.1029/91WR02896.

Bennartz, R., and G. W. Petty, 2001: The sensitivity of microwave remote sensing observations of precipitation to ice particle size distributions. J. Appl. Meteor., 40, 345-364, doi:10.1175/ 1520-0450(2001)040<0345:TSOMRS $>2.0 . C O ; 2$.

Boyd, E., R. J. Cornforth, P. J. Lamb, A. Tarhule, M. I. Lélé, and A. Brouder, 2013: Building resilience to face recurring environmental crisis in African Sahel. Nat. Climate Change, 3, 631637, doi:10.1038/nclimate1856.

Chadwick, R., and D. Grimes, 2012: An artificial neural network approach to multispectral rainfall estimation over Africa. J. Hydrometeor., 13, 913-931, doi:10.1175/JHM-D-11-081.1.

Chen, R., Z. Li, R. J. Kuligowski, R. Ferraro, and F. Weng, 2011: A study of warm rain detection using A-Train satellite data. Geophys. Res. Lett., 38, L04804, doi:10.1029/2010GL046217.

Chou, M.-D., and M. J. Suarez, 1999: A solar radiation parameterization for atmospheric studies. NASA Tech. Memo. NASA/TM-1999-104606, Vol. 15, 38 pp. [Available online at http://gmao.gsfc.nasa.gov/pubs/tm/docs/Chou136.pdf.]

$\longrightarrow,-$, X.-Z. Liang, and M. M.-H. Yan, 2001: A thermal infrared radiation parameterization for atmospheric studies. NASA Tech. Memo. NASA/TM-2001-104609, 56 pp. [Available online at http://gmao.gsfc.nasa.gov/pubs/tm/docs/Chou137.pdf.]

Devereux, S., 2007: The impact of droughts and floods on food security and policy options to alleviate negative effects. Agric. Econ., 37, 47-58, doi:10.1111/j.1574-0862.2007.00234.x.

Dinku, T., P. Ceccato, E. Grover-Kopec, M. Lemma, S. J. Connor, and C. F. Ropelewski, 2007: Validation of satellite rainfall products over East Africa's complex topography. Int. J. Remote Sens., 28, 1503-1526, doi:10.1080/01431160600954688.

,$- \ldots$, and S. J. Connor, 2011: Challenges of satellite rainfall estimation over mountainous and arid parts of East Africa. Int. J. Remote Sens., 32, 5965-5979, doi:10.1080/01431161.2010.499381.

Diro, G. T., E. Black, and D. Grimes, 2008: Seasonal forecasting of Ethiopian spring rains. Meteor. Appl., 15, 73-83, doi:10.1002/met.63.

Ferraro, R. R., 1997: SSM/I derived global rainfall estimates for climatological applications. J. Geophys. Res., 102, 1671516735, doi:10.1029/97JD01210.

Gissila, T., E. Black, D. Grimes, and J. Slingo, 2004: Seasonal forecasting of the Ethiopian summer rains. Int. J. Climatol., 24, 1345-1358, doi:10.1002/joc.1078.

Grell, G. A., and D. Dévényi, 2002: A generalized approach to parameterizing convection combining ensemble and data assimilation techniques. Geophys. Res. Lett., 29, 1693, doi:10.1029/ 2002 GL015311. 
Grimes, D., E. Pardo-Igzquiza, and R. Bonifacio, 1999: Optimal areal rainfall estimation using rain gauges and satellite data. J. Hydrol., 222, 93-108, doi:10.1016/S0022-1694(99)00092-X.

Habib, E., M. ElSaadani, and A. Haile, 2012: Climatology-focused evaluation of CMORPH and TMPA satellite rainfall products over the Nile basin. J. Appl. Meteor. Climatol., 51, 2105-2121, doi:10.1175/JAMC-D-11-0252.1.

Han, M., S. A. Braun, W. S. Olson, P. O. G. Persson, and J. W. Bao, 2010: Application of TRMM PR and TMI measurements to assess cloud microphysical schemes in the MM5 for a winter storm. J. Appl. Meteor. Climatol., 49, 1129-1148, doi:10.1175/ 2010JAMC2327.1.

Hirpa, F., M. Gebremichael, and T. Hopson, 2010: Evaluation of high-resolution satellite precipitation products over very complex terrain in Ethiopia. J. Appl. Meteor. Climatol., 49, 1044-1051, doi:10.1175/2009JAMC2298.1.

Hong, S.-Y., Y. Noh, and J. Dudhia, 2006: A new vertical diffusion package with an explicit treatment of entrainment processes Mon. Wea. Rev., 134, 2318-2341, doi:10.1175/MWR3199.1.

Houze, R. A., Jr., 2012: Orographic effects on precipitating clouds. Rev. Geophys., 50, RG1001, doi:10.1029/2011RG000365.

Huffman, G. J., and Coauthors, 2007: The TRMM Multisatellite Precipitation Analysis (TMPA): Quasi-global, multiyear, combined-sensor precipitation estimates at fine scales. $J$. Hydrometeor., 8, 38-55, doi:10.1175/JHM560.1.

Johnson, B. J., G. W. Petty, and G. Skofronick-Jackson, 2012: Microwave properties of ice-phase hydrometeors for radar and radiometers: Sensitivity to model assumptions. J. Appl. Meteor. Climatol., 51, 2152-2171, doi:10.1175/JAMC-D-11-0138.1.

Joyce, R. J., J. E. Janowiak, P. A. Arkin, and P. Xie, 2004: CMORPH: A method that produces global precipitation estimates from passive microwave and infrared data at high spatial and temporal resolution. J. Hydrometeor., 5, 487-503, doi:10.1175/1525-7541(2004)005<0487:CAMTPG>2.0.CO;2.

Kummerow, C., and Coauthors, 2001: The evolution of the Goddard profiling algorithm (GPROF) for rainfall estimation from passive microwave sensors. J. Appl. Meteor., 40, 1801-1820, doi:10.1175/1520-0450(2001)040<1801:TEOTGP > 2.0.CO;2.

Lorenz, C., and H. Kunstmann, 2012: The hydrological cycle in three state-of-the-art reanalyses: Intercomparison and performance analysis. J. Hydrometeor., 13, 1397-1420, doi:10.1175/ JHM-D-11-088.1.

Maidment, R. I., D. I. F. Grimes, and E. Tarnavsky, 2012: Rainfall data generation and analysis for African meteorology. Climate Change, Agriculture and Food Security Tech. Rep., 26 pp.

,-- , R. P. Allan, H. Greatrex, O. Rojas, and O. Leo, 2013: Evaluation of satellite-based and model re-analysis rainfall estimates for Uganda. Meteor. Appl., 20,308-317, doi:10.1002/ met.1283.

E. Tarnavsky, M. Stringer, T. Hewison, R. Roebeling, and E. Black, 2014: The 30 year TAMSAT African Rainfall Climatology and Time Series (TARCAT) data set. J. Geophys. Res. Atmos., doi:10.1002/2014JD021927, in press.

McCollum, J. R., A. Gruber, and M. B. Ba, 2000: Discrepancy between gauges and satellite estimates of rainfall in equatorial Africa. J. Appl. Meteor., 39, 666-679, doi:10.1175/ 1520-0450-39.5.666.

Morrison, H., J. A. Curry, and V. I. Khvorostyanov, 2005: A new double-moment microphysics parameterization for application in cloud and climate models. Part I: Description. J. Atmos. Sci., 62, 1665-1677, doi:10.1175/JAS3446.1.
Novella, N. S., and W. M. Thiaw, 2013: African Rainfall Climatology version 2 for famine early warning systems. J. Appl. Meteor. Climatol., 52, 588-606, doi:10.1175/ JAMC-D-11-0238.1

Olson, W. S., and Coauthors, 2006: Precipitation and latent heating distributions from satellite passive microwave radiometry. Part I: Improved method and uncertainties. J. Appl. Meteor. Climatol., 45, 702-720, doi:10.1175/JAM2369.1.

Petty, G. W., 1999: Prevalence of precipitation from warm-topped clouds over eastern Asia and the western Pacific. J. Climate, 12, 220-229, doi:10.1175/1520-0442-12.1.220.

Romilly, T., and M. Gebremichael, 2011: Evaluation of satellite rainfall estimates over Ethiopian river basins. Hydrol. Earth Syst. Sci., 15, 1505-1514, doi:10.5194/hess-15-1505-2011.

Schneider, U., A. Becker, P. Finger, A. Meyer-Christoffer, M. Ziese, and B. Rudolf, 2014: GPCC's new land surface precipitation climatology based on quality-controlled in situ data and its role in quantifying the global water cycle. Theor. Appl. Climatol., 115, 15-40, doi:10.1007/s00704-013-0860-x.

Skamarock, W. C., and Coauthors, 2008: A description of the Advanced Research WRF version 3. NCAR Tech. Note NCAR/TN-475+STR, 113 pp., doi:10.5065/D68S4MVH.

Tarnavsky, E., D. I. F. Grimes, R. I. Maidment, M. Stringer, R. Chadwick, R. P. Allan, E. Black, and F. Kayitakire, 2014: Extension of the TAMSAT satellite-based rainfall monitoring over Africa and from 1983 to present. J. Appl. Meteor. Climatol., doi:10.1175/JAMC-D-14-0016.1, in press.

Thorne, V., P. Coakeley, D. Grimes, and G. Dugdale, 2001: Comparison of TAMSAT and CPC rainfall estimates with rain gauges, for southern Africa. Int. J. Remote Sens., 22, 19511974, doi:10.1080/01431160118816.

Todd, M. C., E. C. Barrett, M. J. Beaumont, and J. L. Green, 1995: Satellite identification of rain days over the upper Nile River basin using an optimum infrared rain no-rain threshold temperature model. J. Appl. Meteor., 34, 2600-2611, doi:10.1175/ 1520-0450(1995)034<2600:SIORDO >2.0.CO;2.

,,--- , and T. J. Bellerby, 1999: Estimation of daily rainfall over the upper Nile River basin using a continuously calibrated satellite infrared technique. Meteor. Appl., 6, 201210, doi:10.1017/S1350482799001206.

Tompkins, A. M., and A. A. Adebiyi, 2012: Using CloudSat cloud retrievals to differentiate satellite-derived rainfall products over West Africa. J. Hydrometeor., 13, 1810-1816, doi:10.1175/ JHM-D-12-039.1.

Verdin, J., C. Funk, G. Senay, and R. Choularton, 2005: Climate science and famine early warning. Philos. Trans. Roy. Soc. London, B360, 2155-2168, doi:10.1098/rstb.2005.1754.

Washington, R., and Coauthors, 2006: African climate change: Taking the shorter route. Bull. Amer. Meteor. Soc., 87, 13551366, doi:10.1175/BAMS-87-10-1355.

Weng, F., L. Zhao, R. Ferraro, G. Poe, X. Li, and N. Grody, 2003: Advanced microwave sounding unit cloud and precipitation algorithms. Radio Sci., 38, 8068-8079, doi:10.1029/ 2002RS002679.

Wicker, L. J., and W. C. Skamarock, 2002: Time-splitting methods for elastic models using forward time schemes. Mon. Wea. Rev., 130, 2088-2097, doi:10.1175/1520-0493(2002)130<2088: TSMFEM $>2.0 . \mathrm{CO} ; 2$.

Zhao, L., and F. Weng, 2002: Retrieval of ice cloud parameters using the Advanced Microwave Sounding Unit. J. Appl. Meteor., 41, 384-395, doi:10.1175/1520-0450(2002)041<0384: ROICPU $>2.0 . \mathrm{CO} ; 2$ 